\title{
TEXTURE OF METALS
}

\author{
HSUN HU \\ United States Steel Corporation, Research Laboratory, Monroeville \\ Pennsylvania 15146, U.S.A.
}

(Received March 1, 1974)

\begin{abstract}
A condensed review of casting, deformation, and annealing textures of polycrystalline metals and alloys is presented. It is intended to provide an informative but simplified reference for researchers, engineers, and students who are seeking quick information on the development of textures in various metal objects, and for those who are primarily interested in the textures of non-metallic materials, but wish to acquire a general background knowledge on the texture formation in metals.
\end{abstract}

\section{INTRODUCTION}

Metals are crystalline in the solid state. In a polycrystalline aggregate each grain is an individual crystal differing from its neighboring grains in lattice orientation. At any stage of the manufacturing process, it is seldom that the crystals are oriented completely at random. In castings, columnar grains can form along a specific crystallographic direction during solidification. During subsequent plastic deformation, the crystals rotate toward certain stable orientations. Upon recrystallization, new crystals form and grow preferentially at the expense of the deformed matrix crystal. All these processes lead to the development of nonrandomness of the grain orientations in a polycrystalline aggregate, known as preferred orientations, or textures. The nature of the texture developed in a particular specimen depends on the material and on the mechanical and thermal treatments.

Many of the physical, mechanical, and even chemical properties of single crystals vary with the crystallographic direction or plane. Accordingly, a textured material usually exhibits anisotropic properties. Depending on the nature of the texture and the intended use of the material, property anisotropy may or may not be a desirable feature from the practical point of view. To fully utilize the property anisotropy to advantage, it is often necessary to "tailor-make" a texture for a particular purpose. Much research, both industrial and academic, on the development of textures and the principles governing such development has been conducted in recent years.
Data on textures of metals are voluminous in the literature. In this article, only a brief account of textures in castings, deformed metals and annealed metals will be given. For detailed information, the reader is advised to look into the general references listed at the end of the paper. For compactness of this presentation, individual references were purposely deleted.

\section{CASTING TEXTURES}

\section{Structure of Metal Castings}

The macrostructure of a metal casting may vary considerably depending upon the conditions during solidification. In pure metals, the structure after solidification is often entirely columnar, if the freezing rate is slow and if the metal solidifies with little turbulence. The casting structure of solidsolution alloys is usually characterized by regions of equiaxed grains; in many instances columnar crystallization may be completely absent. However, the as-cast ingot structure of austenitic $\mathrm{Cr}-\mathrm{Ni}$ alloys, e.g. the 18-8 or 304-type stainless steels, can be entirely columnar. Hence, the structure of an alloy casting depends not only upon the conditions under which the liquid metal is cast and solidified, but also upon the composition of the alloy, as well as its thermal and constitutional characteristics.

In general, the structure of a metal casting may contain three distinguishable zones: (1) the chillcast zone in which small crystals of various orientations are formed next to the mold wall; (2) the 
columnar zone, which contains elongated crystals with certain crystallographic directions aligned in the direction of heat-flow or crystal growth; and (3) the interior equiaxed zone, where essentially equiaxed grains are crystallized from the last portion of the liquid metal in the mold. The chillcast grains may or may not have a preferred orientation, whereas the orientation of the interior equiaxed grains is always random. A relatively strong texture is usually associated with the columnar grains. This is attributed to a preferred direction of growth, which is apparently related to dendritic growth due to supercooling, and to growth competition among the new grains.

\section{Texture of Metal Castings}

The preferred orientations of metal castings differ from metal to metal, depending mainly upon the crystal structure of the metal. For cubic ( fcc and bcc) metals or alloys, a [100] direction is usually parallel to the long axis of the columnar grains, or perpendicular to the mold wall; other crystallographic axes are oriented at random around this [100] direction. Preferred orientations of this nature are commonly called fiber textures; these are usually specified by the crystallographic direction lying parallel to the fiber axis.

There are exceptions, although these may be a consequence of a change in freezing morphology because of compositional or experimental variations. For example, the columnar grains in $\mathrm{Pb}$ castings normally have a [100] direction parallel to their long axis, but in zone-refined $\mathrm{Pb}$ after unidirectional solidification the common axis is [111]. With a small addition of $\mathrm{Ag}$ (5 ppm by weight), the [100] texture is restored. For $\mathrm{Al}$, raising the pouring temperature to $860^{\circ} \mathrm{C}$ results in a random casting texture, instead of the normal [100]-type preferred orientation.

Among the bcc metals, iron and steels can undergo successive phase transformations of $\delta(\mathrm{bcc}) \rightarrow$ $\gamma(\mathrm{fcc}) \rightarrow \alpha(\mathrm{bcc})$ upon cooling. Their casting textures would be widely scattered if the twenty-four crystallographic variants of the Kurdjumov-Sachs orientation relationships (closest-packed planes and directions of both phases coincide) for fcc $\rightleftarrows$ bcc transformations occurred with equal probability. However, the casting texture of ingot iron was reported in 1926 to be [100]. In a continuously cast slab of low-carbon steel, the columnar zone showed a preferred orientation of [110]. Such an orienta- tion of the $\alpha$-ferrite can be derived from a [100] orientation of the austenite according to the $\mathrm{K}-\mathrm{S}$ relationships. This would imply that the austenite adopted the orientation of the $\delta$-ferrite which froze in a [100] preferred orientation.

In hcp metals the casting texture appears to depend on the c/a ratio. Cadmium and zinc, both having axial ratios greater than that for ideal closepacking $(\mathrm{c} / \mathrm{a}=1.633)$, develop the same casting texture. Magnesium has an axial ratio slightly less than 1.633; accordingly, its casting texture differs from that of $\mathrm{Cd}$ or $\mathrm{Zn}$. Castings of other noncubic metals develop their own characteristic orientations.

The casting textures of various metals and alloys are summarized in Table $I$.

\section{DEFORMATION TEXTURES}

\section{Reorientation in Plastic Deformation}

Plastic deformation occurs in metal crystals by slip or by twinning on certain atomic planes and in specific crystallographic directions, the so-called "slip or twinning systems." In fcc metals, the slip systems are $\{111\}\langle 110\rangle$, whereas deformation faulting or mechanical twinning systems are $\{111\}\langle 112\rangle$. In bcc metals, the slip direction is always $\langle 111\rangle$, but the slip planes can be $\{110\},\{112\}$ and, perhaps $\{123\}$ with or without preference, depending on metal or the deformation temperature; twinning occurs on $\{112\}\langle 111\rangle$. In hcp metals, the most common slip and twinning systems are (0001) $\langle 11 \overline{2} 0\rangle$ and $\{101 \overline{2}\}\langle\overline{1} 011\rangle$ respectively, but other slip planes and twinning systems may also prevail depending on the $\mathrm{c} / \mathrm{a}$ ratio and other factors. The deformation mechanisms in other noncubic metals are usually more complex, because of low crystal-symmetry.

Although mechanical twinning induces an abrupt change in orientation of the twinned material, large plastic strains are obtained usually by slip. During the slip process, the crystal lattice also rotates so that the active slip direction (in uniaxial tension) or the active slip-plane normal (in uniaxial compression) moves toward alignment with the direction of the applied stress. As a consequence, the orientation of the crystal changes during deformation. In a polycrystalline specimen, even though the grains are initially oriented at random, after sufficient deformation most of the grains are realigned into a preferred orientation, hence the development of a texture. 
TABLE I

Casting textures of metals and alloys

\begin{tabular}{|c|c|c|}
\hline Metal or Alloy & Structure & $\begin{array}{l}\text { Fiber Axis of } \\
\text { Columnar Grains }\end{array}$ \\
\hline $\begin{array}{l}\mathrm{Al}, \mathrm{Cu}, \mathrm{Ag}, \mathrm{Au}, \mathrm{Ni}, \mathrm{Pb} \\
\text { Dilute alloys of } \mathrm{Al}, \mathrm{Mn}, \mathrm{P}, \mathrm{Sn} \text { in } \mathrm{Cu} \\
\alpha \text {-brass } \\
\mathrm{Ni}-20 \text { wt. } \% \mathrm{Cr} \\
\text { Ni-base superalloys } \\
18-8 \text { type stainless steels }\end{array}$ & FCC & {$[100]$} \\
\hline $\begin{array}{l}\mathrm{Cr}, \mathrm{Mo} \text {, Ingot-Fe } \\
\text { Dilute alloys of } \mathrm{Si} \text { in } \mathrm{Fe} \\
\text { Fe-Ni-Al permanent-magnet alloys } \\
\text { Ferritic Cr stainless steels } \\
\beta \text {-brass } \\
\text { Low-C steels (continuously cast slab) }\end{array}$ & $\mathrm{BCC}$ & [100] \\
\hline $\begin{array}{l}\mathrm{Cd}(\mathrm{c} / \mathrm{a}=1.885) \\
\mathrm{Zn}(\mathrm{c} / \mathrm{a}=1.856) \\
\mathrm{Mg}(\mathrm{c} / \mathrm{a}=1.624)\end{array}$ & HCP & $\begin{array}{l}{[10 T 0]} \\
{[2 \overline{1} 10]}\end{array}$ \\
\hline $\begin{array}{l}\beta-\mathrm{Sn} \\
\mathrm{Bi}\end{array}$ & $\begin{array}{l}\text { Tetragonal } \\
\text { Rhombohedral }\end{array}$ & $\begin{array}{l}{[110]} \\
{[111]}\end{array}$ \\
\hline
\end{tabular}

\section{Nature of Deformation Textures}

The nature of the deformation texture depends essentially on the crystal structure of the metal, and on the nature and extent of plastic flow. Many other factors, such as composition, initial texture, thermal and mechanical history, and the temperature, rate, and physical constraints during deformation, may all affect the resulting texture to some extent. There have been numerous attempts in the development of a working theory of deformation textures, but only limited success has been obtained.

\section{Deformation Textures in Wires or Rods}

Wire and rod produced by drawing, swaging, rodrolling, or extrusion (constrained tensile deformation) usually develop preferred orientations that are uniaxial or fibrous. One or two specific crystallographic directions are oriented parallel to the wire or rod axis, whereas other crystallographic directions are distributed more or less at random around this axis (fiber texture). Frequently, a preferred orientation may also develop in the radial direction (cyclic texture). In general, the texture is more diffuse and complex at the surface than in the interior. This usually arises from frictional forces at the surface during forming operations. The nature of the texture depends essentially on the crystal structure and on material and processing variables.

In fcc metals, the fiber texture is usually composed of duplex components, the [111] and [100]. The relative amount of these two components varies from metal to metal. In aluminum, the texture is predominantly [111], whereas in silver a high concentration of [100] is developed. Lead is reportedly similar to aluminum. Other common fcc metals, such as $\mathrm{Cu}, \mathrm{Ni}$, and $\mathrm{Au}$, develop duplex [111]+ [100] fiber textures with various relative concentrations that are intermediate between those of $\mathrm{Al}$ and Ag. With increasing [100] (or decreasing [111]) component, these metals can be arranged in the order of $\mathrm{Al}, \mathrm{Au}, \mathrm{Ni}, \mathrm{Cu}$, and $\mathrm{Ag}$, which is approximately the same as the order of decreasing stacking fault energy. Thus, the variation of fiber texture components in fcc metals appears to be related to the stacking fault energy of each metal.

The addition of alloying elements to a pure metal usually decreases the stacking fault energy. Accordingly, the relative concentration of the [100] component tends to increase. However, for alloys of very low stacking fault energies, a reverse trend has been observed. The relative concentrations of 
the fiber texture components may be influenced also by a number of other factors, such as the amount, the temperature, and the rate of deformation, as well as the initial texture, the grain size, and the purity of the material. Recrystallization may occur in a high-purity metal during severe deformation or during forming at an elevated temperature, and the resulting texture will be affected.

Table II summarizes the trend of variation of fiber texture in fcc metals and alloys. A typical duplex fiber texture is shown in Figure 1.

\section{TABLE II}

Variation of fiber texture components in wires or rods of fcc metals and alloys

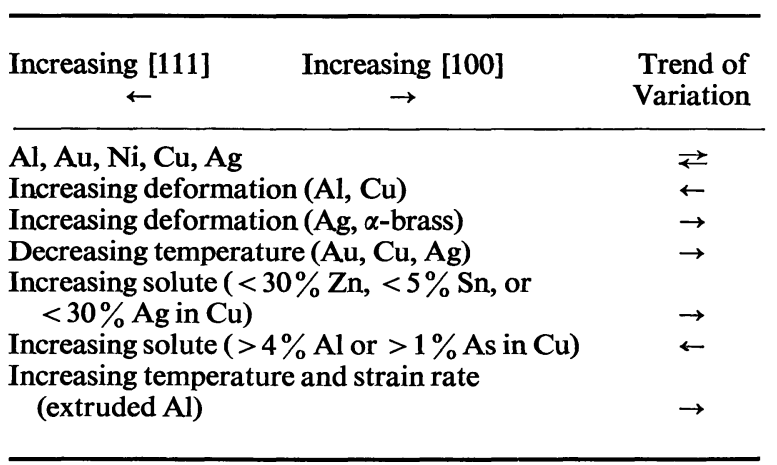

In bcc metals, the fiber texture is a simple [110]. No minor components were detected in $\mathrm{V}, \mathrm{Nb}, \mathrm{Ta}$, Mo, W, or Fe. Bcc alloys, such as plain carbon steels, silicon-ferrite, and $\beta$-brass, also develop a simple [110] texture.

High-strength, patented eutectoid steel wires have a [110] texture but less sharp than that of $\mathrm{Fe}$ wires. This is probably due to the fact that the harder cementite phase disturbs the flow of the ferrite during drawing, and distorts the ferrite texture. Also, eutectoid steel wires drawn at a low speed show a slightly sharper texture than those drawn at a high speed.

In hcp metals, there is an indication that the fiber texture of extruded rods or drawn wires depends on thec/a ratio. In those metals having $\mathrm{c} / \mathrm{a}<1.633$ (ideal close-packing), such as $\mathrm{Zr}, \mathrm{Ti}$, and $\mathrm{Be}$, the fiber axis is [1010]. For zinc (c/a $>1.633)$, the $c$ axis is either parallel or nearly perpendicular to the rod or wire axis. In the latter case, there is no preferred alignment of the directions in the basal plane with the rod or wire axis. The axial ratio of $\mathrm{Mg}$ is very close to that of the ideal close-packing. Its fiber-texture characteristics are intermediate between those of $\mathrm{Zn}$ and $\mathrm{Zr}, \mathrm{Ti}$, or $\mathrm{Be}$. However, the textures of $\mathrm{Zn}$ and of $\mathrm{Mg}$ deformed at elevated temperatures, may include complications from concurrent recrystalliza-

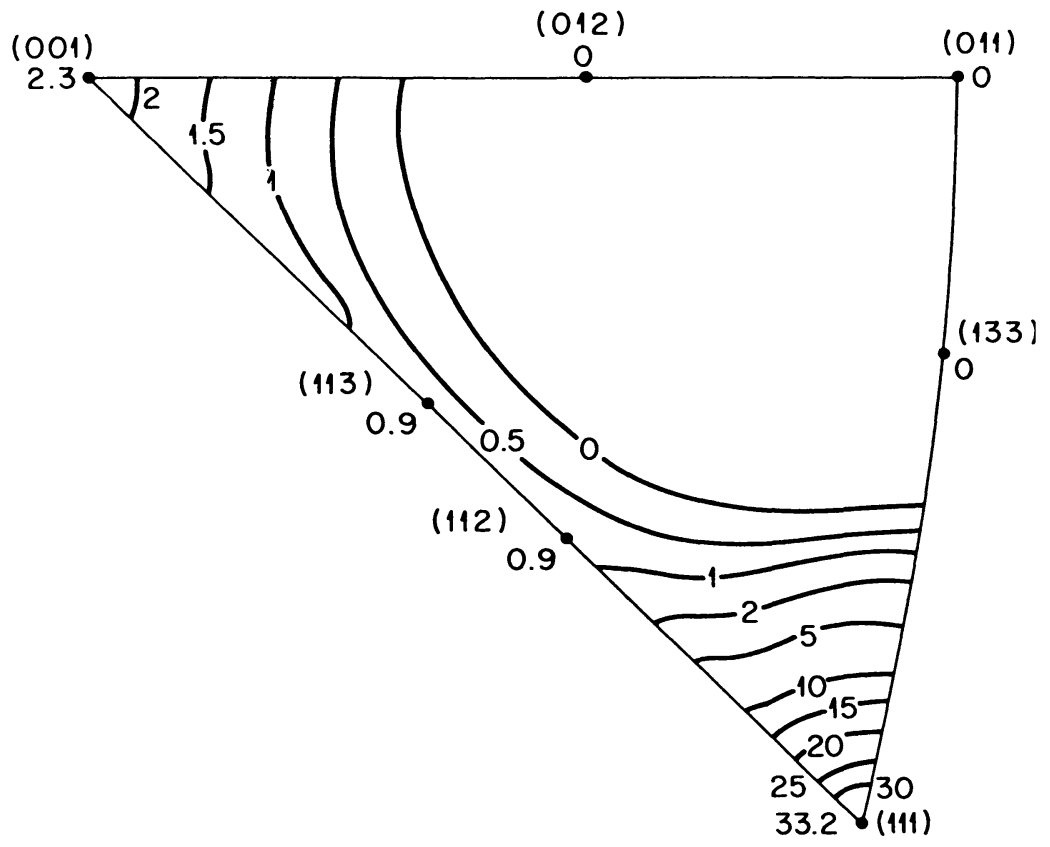

FIGURE 1 Fiber axis distribution chart, or inverse pole figure, for aluminum rod extruded at $-196^{\circ} \mathrm{C}$ to 91.7 pct reduction at $1 \mathrm{fpm}$. (McHarque, Jetter, and Ogle, Trans. TMS-AIME, 215, 831, 1959.) 
tion. Table III summarizes the fiber textures observed in hep metals and alloys.

Swaged, rolled, or extruded rods of orthorhombic $\alpha$-uranium have a duplex fiber texture, which can be described as approximately $[010]+[410]$, as shown in Figure 2. These directions correspond to the poles of (010) and (110) planes. A cyclic preferred orientation with (001) poles in the radial direction is frequently developed. The relative concentrations of the fiber texture components vary with tempera-

TABLE III

Fiber textures in wires or rods of hcp metals and alloys

\begin{tabular}{|c|c|c|}
\hline Metal & Forming Process & Fiber Axis \\
\hline $\begin{array}{l}\mathrm{Zn} \\
\quad(\mathrm{c} / \mathrm{a}=1.856) \\
\mathrm{Zn-alloy} \\
\quad(10 \mathrm{Al}, 2 \mathrm{Cu}, 0.03 \mathrm{Mg})\end{array}$ & $\begin{array}{l}\text { Drawing } \\
\text { Extrusion } \\
\text { Extrusion }\end{array}$ & $\begin{array}{l}\text { [0001] (low reductions) } \\
\sim 70^{\circ}[0001] \text { (high reductions) } \\
{[0001]+90^{\circ}[0001]} \\
90^{\circ}[0001]\end{array}$ \\
\hline $\begin{array}{l}\mathrm{Mg} \\
\quad(\mathrm{c} / \mathrm{a}=1.624) \\
\text { Dowmetal } \\
\quad(\mathrm{Mg}-\mathrm{Al}, \mathrm{Mn}, \mathrm{Zn})\end{array}$ & $\begin{array}{l}\text { Drawing } \\
\text { Extrusion }\left(125^{\circ} \mathrm{C}\right) \\
\text { Extrusion or drawing } \\
\quad\left(>450^{\circ} \mathrm{C}\right) \\
\quad\left(<450^{\circ} \mathrm{C}\right)\end{array}$ & $\begin{array}{l}90^{\circ}[0001] \\
\sim 80^{\circ}[0001] \\
{[2110]} \\
{[1010]}\end{array}$ \\
\hline${ }_{(\mathrm{c} / \mathrm{a}=1.589)}^{\mathrm{Zr}}$ & Drawing & {$[10 \overline{1} 0]$} \\
\hline $\mathrm{Ti}_{(\mathrm{c} / \mathrm{a}=1.587)}$ & Wire-rolling & [10T̄0] \\
\hline $\begin{array}{l}\mathrm{Be} \\
\quad(\mathrm{c} / \mathrm{a}=1.568)\end{array}$ & $\begin{array}{l}\text { Extrusion or drawing } \\
\left(1100-1150^{\circ} \mathrm{C}\right)\end{array}$ & [10̄̄o] \\
\hline
\end{tabular}

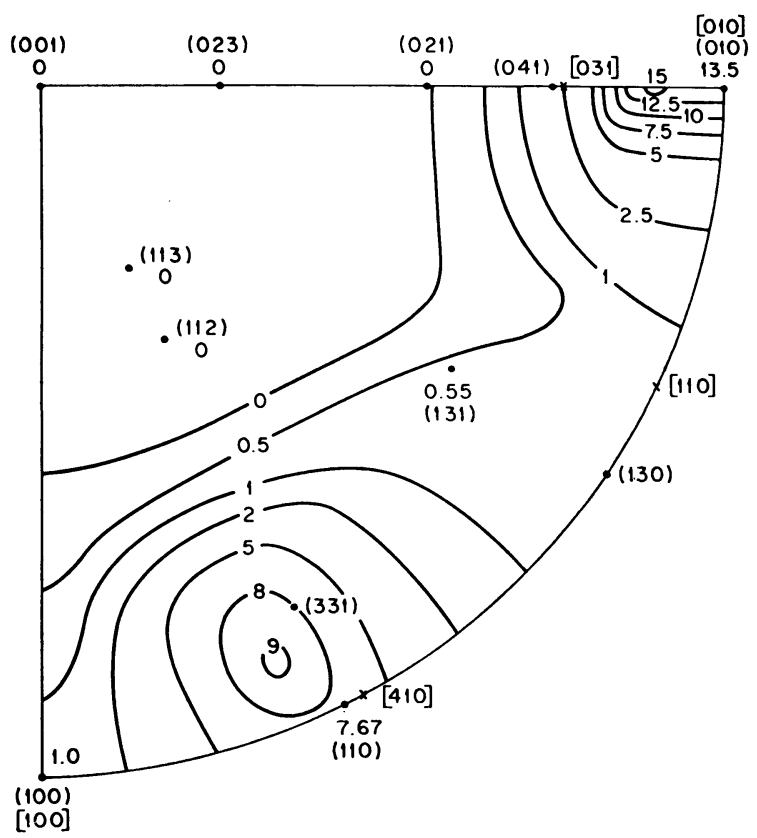

FIGURE 2 Fiber axis distribution chart or inverse pole figure for uranium rod extruded at $500^{\circ} \mathrm{C}$ to $91.7 \mathrm{pct}$ reduction in area. (Jetter and McHarque, Trans. AIME, 209, 291, 1957.) ture and amount of deformation. At low deformation temperatures, the [010] component predominates. Increasing deformation and higher temperatures favor the development of the [410] component. In nuclear-reactor applications, the anisotropic expansion and contraction of textured uranium fuel-rods present serious difficulties. These have to be overcome by strict control of the textures.

Roll-flattening a wire of some fcc metals or alloys can produce a tape with a strong [111] texture in the rolling direction. Such tapes can be used for improved magnetic, elastic, or plastic properties.

\section{Deformation Textures in Tubes}

In tube forming the nature of the texture developed depends on the relative reductions of wall thickness and tube diameter. When the wall thickness and tube diameter are reduced proportionally, the texture is similar to that in a rod or wire. If only the wall thickness is reduced, the texture resembles that of a rolled sheet (textures in rolled sheets will be discussed in a later section). Sinking the tube, i.e., when the tube diameter is reduced without reducing the wall thickness, tends to develop preferred 
directions tangential to the circumference. Since in tube forming the reduction ratio of wall thickness to tube diameter can be varied at will, the resulting texture can be controlled within wider limits in production than can textures in wire or rod drawing or flat-sheet rolling. However, published data on tube textures are rather limited.

\section{Compression Textures}

Uniaxial compression produces preferred orientations that are quite different from those produced by simple tension or constrained tension. This arises from the fact that in compression, when deformation occurs by single slip, the active slip-plane normal rotates toward the compression axis, whereas in tension it is the active slip direction that tends to align with the axis of the applied stress. In the compression of a polycrystalline aggregate, where multiple slip occurs, the direction of lattice rotation is opposite to that in tension. Thus, the stable endorientations in tension and in compression are different.

The preferred orientation produced by compression-rolling $\dagger$ is a fiber-type texture with the compression axis as the fiber axis. As in wire or rod textures, the compression textures of $f c c$ metals and alloys are not all the same. For most fcc pure metals, with the possible exception of $\mathrm{Ag}$, the compression texture consists of a strong component around [110], a spread from [110] to [113], plus a weak component around [100], while orientations around the [111] axis are nearly absent. For many fcc alloys, such as $\alpha$-brasses $(10-30 \% \mathrm{Zn})$ and $\mathrm{Cu}-\mathrm{Al}$ alloys $(4-8 \% \mathrm{Al})$, the [110] component still predominates, the spread is again from [110] to [113], but the minor component is around the [111] axis; orientations near the [100] axis are practically absent. Copper-nickel alloys behave like a pure metal in compression-texture development. These textural characteristics appear to be related to the stacking fault energy of the metal or alloy. For bcc metals and alloys, such as $\mathrm{Fe}$ and $\mathrm{Si}$-ferrite, the compression texture is a duplex [111] $+[100]$, with [111] being the major component. Among hcp metals or alloys, the compression texture of $\mathrm{Mg}$ and its alloy Dowmetal is [0001]. In compressed or compressionrolled $\mathrm{Ti}$, the [0001] axis is tilted with respect to the

\footnotetext{
† Rolling in a slightly different direction in successive passes. A main feature in compression-rolling is that much larger total strains can be obtained more readily than in uniaxial compression.
}

compression axis; the angle of tilt decreases from approximately 30 to $15^{\circ}$ with increasing reduction. Hafnium behaves similarly.

\section{Deformation Textures in Rolled Sheets}

The description of sheet textures While fiber textures can be adequately described by an axisdistribution chart, or inverse pole figure, which is readily obtainable, a statistically complete description of the orientation distribution in sheet textures requires "pole-figure inversion" involving cumbersome mathematical operations. With the help of computers, there has been fair success in this area during recent years, and its application is expected to increase in the future. However, the conventional pole figure, owing to its relative simplicity in determination, remains as the most common method for sheet texture representation at present.

A pole figure is essentially a stereographic projection showing the distribution of a set of $\{\mathrm{hkl}\}$ poles in orientation space. Thus, a uniform distribution of poles represents random crystal orientation, whereas dense clusters of poles indicate strong textures. In the construction of pole figures, it is standard practice to express the density of poles in units of the pole-density in a random sample of the same material. Since polycrystalline sheets usually develop complex textures with considerable orientation spreads, the interpretation of a complicated pole figure in terms of specific orientations is difficult and frequently ambiguous. To improve the situation it is desirable to examine one or two additional pole figures determined for other sets of crystal planes so that the preferred orientations that are present and their relative prominence can be ascertained.

Sheet textures are usually described by "ideal orientations," a simplified means of approximate description of preferred orientation. The symbol (hkl)[uvw] is commonly used to designate that the plane (hkl) lies parallel to the plane of the sheet (or rolling plane), and that the direction [uvw] is parallel to the rolling direction.

For fcc metals, the rolling textures can be classified into two main types. The copper-type, which can be described as having approximately (123)[412]+ (146)[ $\overline{2} \overline{1} 1]$ as its principal ideal orientations, is commonly found in most of the fcc metals, such as $\mathrm{Cu}, \mathrm{Ni}, \mathrm{Au}, \mathrm{Al}$, and $\mathrm{Th}$, etc. The other type, having a principal orientation very close to (110)[112], is found in rolled $\mathrm{Ag}$; hence, it is frequently called the silver-type. The orientation spreads in the two types 


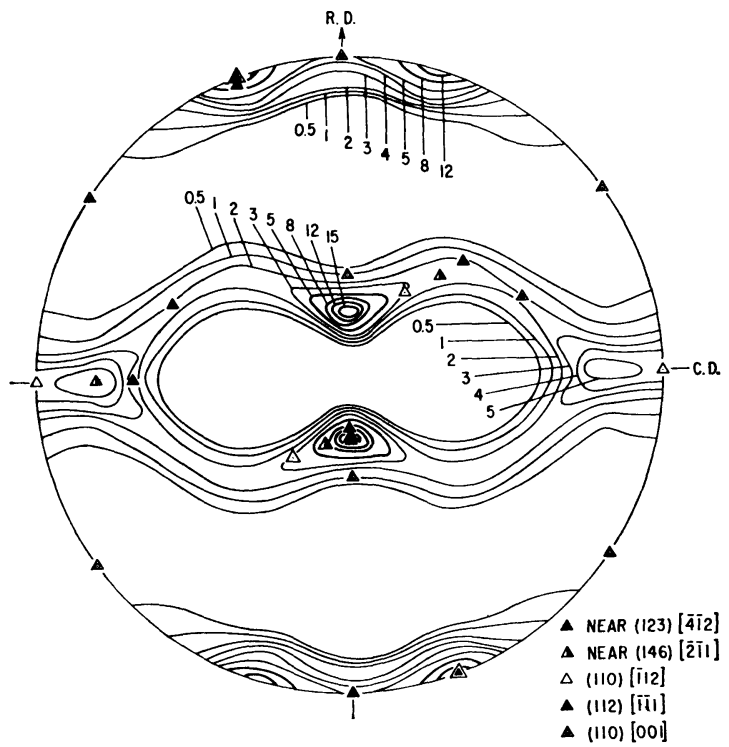

(a)

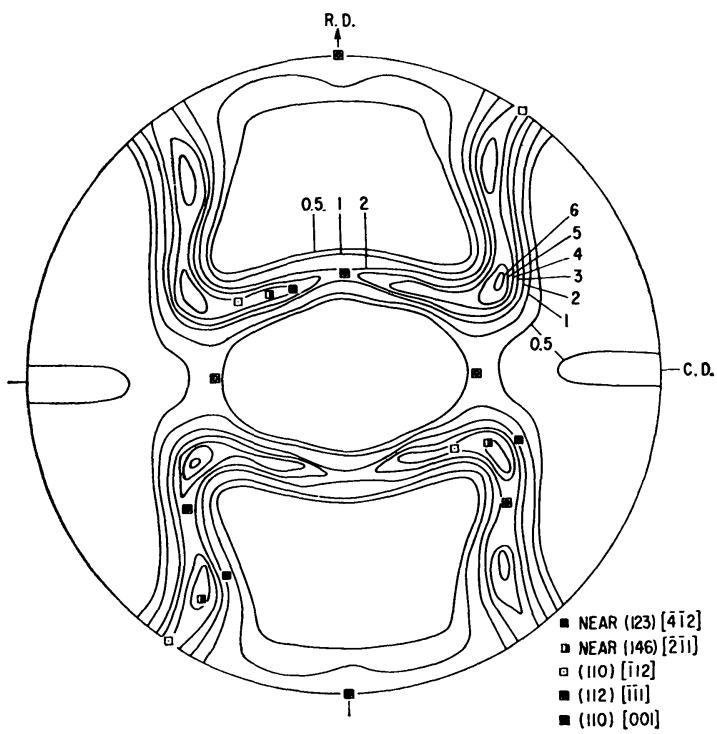

(b)

FIGURE 3 Rolling texture of electrolytic copper after 96.6 pct reduction in thickness at $25^{\circ} \mathrm{C}$. The ideal orientations for both the copper-type and the silver-type textures are indicated. (a) (111) pole figure, (b) (200) pole figure. (Hu and Goodman, Trans. TMS-AIME, 227, 627, 1963.)

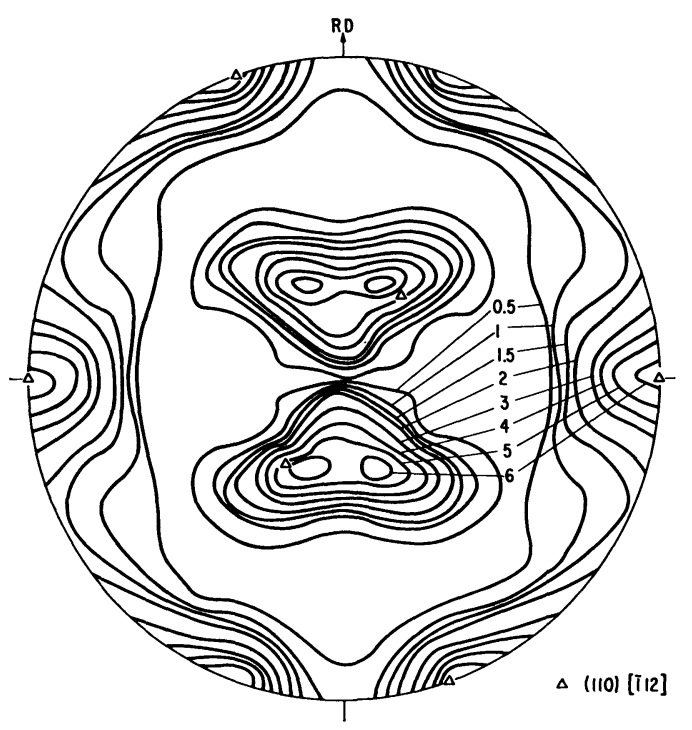

(a)

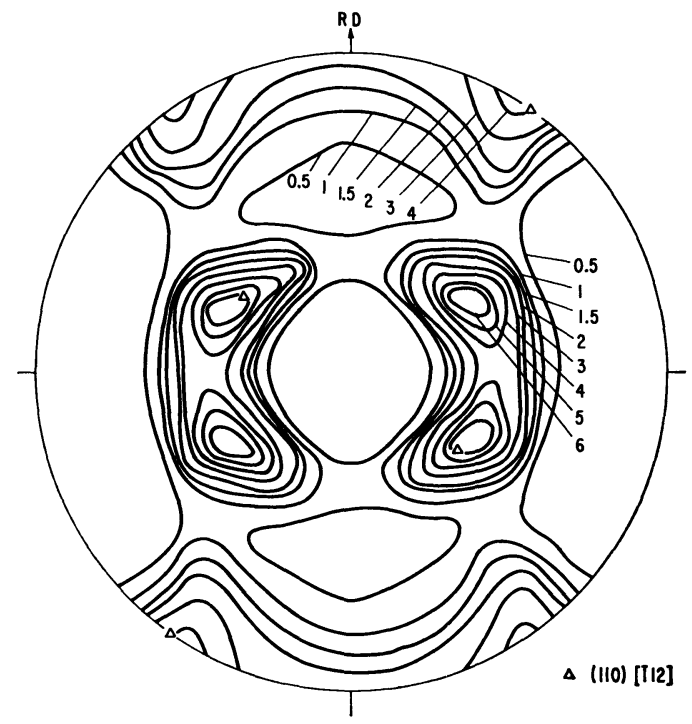

(b)

FIGURE 4 Rolling texture of high-purity silver $\left(99.999^{+}\right.$pct pure), rolled 91 pct at $0^{\circ} \mathrm{C}$. Texture determined at $0^{\circ}$ C. (a) (111) pole figure, (b) (200) pole figure. (Hu and Cline, J. Appl. Phys. 32, 760, 1961.) 
of rolling textures are also distinctly different. In the copper-type textures, the orientation spread around (112)[1111] is fairly prominent, whereas it is nearly absent in the silver-type textures. On the other hand, the orientation spread around (110)[001] is fairly prominent in the silver-type textures, but very weak in the copper-type textures. There is indication that $\mathrm{Rh}$ and $\mathrm{Pd}$ develop copper-type rolling textures, whereas $\mathrm{Yb}$ shows the silver-type. An intermediate texture is indicated by Pt. The rolling textures of $\mathrm{Cu}$ and $\mathrm{Ag}$ are shown respectively in Figures 3 and 4.

It should be pointed out that the differences between the two types of textures appear only after a moderate amount of deformation and are mainly in the relative prominence of the texture components, rather than in their nature. Minor differences may also exist among textures of the same type, but of different materials. The two types of textures represent the end-orientations which are related by rotations around two [111] axes, one being the (111) pole in the plane of the sheet and near the rolling direction, the other being the (111) pole near the normal to the sheet plane tilted toward the rolling direction.

Texture transition from the copper-type to the silver-type can be effected by alloy additions. For a given solvent metal, complete transition of the texture usually requires a minimum solute concentration, which depends on the solute element. A typical example is the addition of $\mathrm{Zn}$ to $\mathrm{Cu}$. The texture changes gradually to the silver-type with increasingsolute concentration, up to approximately $10 \% \mathrm{Zn}$, as shown in Figure 5. Minor components, such as (110)[001] have been observed to peak out at intermediate $\mathrm{Zn}$ contents, a phenomenon approximately similar to the texture reversal in drawn wires. Further additions of $\mathrm{Zn}$ cause little change in texture. Thus, the texture of $70-30$ brass is quite similar to that of pure silver. Hence, the terms silver-type and brass-type are often used synonymously.

On the other hand, the texture of $\mathrm{Ni}$ is practically unchanged by the additions of $\mathrm{Fe}$, even up to $70 \%$, although $10 \%$ Mo or $50 \%$ Co added to Ni changes the texture completely from the copper-type to the silver-type. The fcc alloy $\mathrm{Pu}-3.4$ at. $\% \mathrm{Ga}$ also has a copper-type texture. The general situation of rollingtexture transition is quite similar to that of fibertexture variation in fcc metals and alloys. The transition is apparently associated with the stacking fault energy of the metal or alloy.

Texture transitions of copper-type $\rightleftarrows$ silver-type can also be produced in fcc metals or alloys by changing the temperature of deformation. Figure 6 shows such textural changes in a Type 304L stainless steel. Similar results were reported for $\mathrm{Cu}, \mathrm{Ag}$, and low-Zn brass. The direction of texture transition as affected by varying the deformation temperature is consistent in all cases-a silver-type texture is changed toward the copper-type by raising the temperature of deformation, whereas a copper-type texture changes toward the silver-type by lowering the temperature of deformation. Various theories have been proposed for such texture transitions in fcc metals. Evidence indicates that mechanical twinning and deformation faulting on the $\{111\}$ $\langle 112\rangle$ systems is largely responsible for the formation of silver-type textures. On this basis, no such texture transition should be observed in crossrolling, and this was confirmed in 70-30 brass (see Cross-rolling textures).

Long-range order in $\mathrm{Cu}_{3} \mathrm{Au}$ was reported to have some effect on its rolling texture after moderate deformations, but no detectable difference was observed in the rolling texture of $\mathrm{Ni}_{3} \mathrm{Mn}$, regardless of whether it was nearly fully ordered or disordered prior to rolling.

In all bcc metals the rolling textures are largely the same and the nature of the texture is not appreciably altered by solute additions. The temperature of deformation also has little effect on texture. At low temperatures and in some specific alloys such as $\mathrm{Mo}-35 \% \operatorname{Re}$ and $\mathrm{Ti}-20 \% \mathrm{~V}$, mechanical twinning may occur frequently during early stages of deformation, but as twinning frequency decreases with increasing deformation, slip rotations occurring in the initially twinned material are essentially similar to those in equivalent grains. The rolling texture of bcc metals and alloys can be described as mainly of (001)[110] to (111) [1110], corresponding to rotations of up to $\pm 55^{\circ}$ around the [110] axis in the rolling direction, plus a less prominent orientation spread from (112)[110] to (111)[ $\overline{2} 11]$, corresponding to rotations around an axis nearly in common with the (011) poles of the two orientations $\left(30-35^{\circ}\right.$ tilt from the rolling plane normal toward the rolling direction). Figure 7 shows the rolling texture of $\mathrm{Nb}(\mathrm{Cb})$. The dash and dotted lines are respectively loci of rotations around the axes $A$ and $B$, indicating the nature of the orientation spreads just described. Essentially similar textures were observed in $\mathrm{Fe}, \mathrm{V}, \mathrm{Cr}, \mathrm{Mo}$, $\mathrm{Ta}, \mathrm{W}, \mathrm{Fe}$-alloys with $\mathrm{Al}, \mathrm{Si}, \mathrm{Ni}, \mathrm{Co}, \mathrm{V}$, and $\mathrm{Cr}$, plain carbon steels, the bcc $\mathrm{Ti}-18 \% \mathrm{Nb}$ alloy, and $\beta$-brass. 


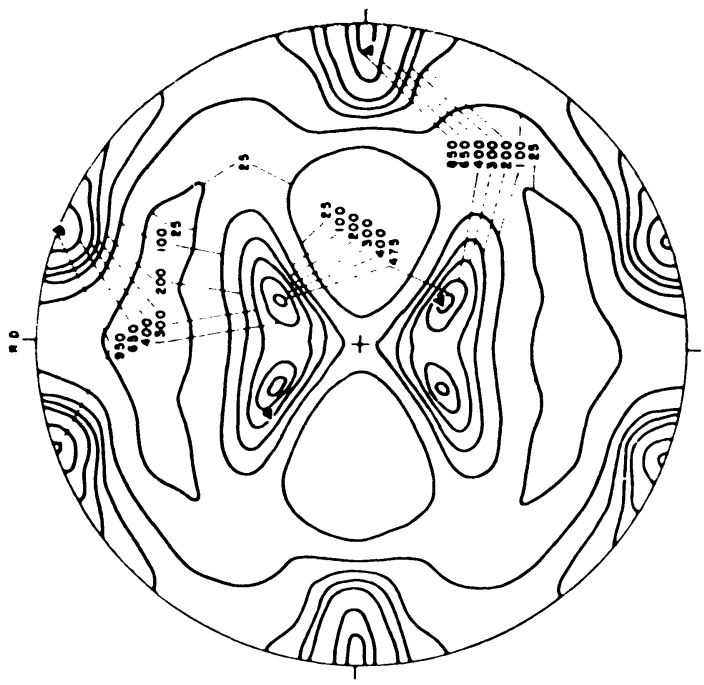

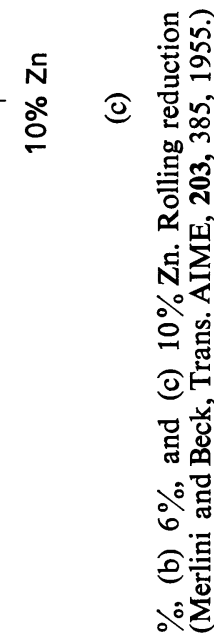

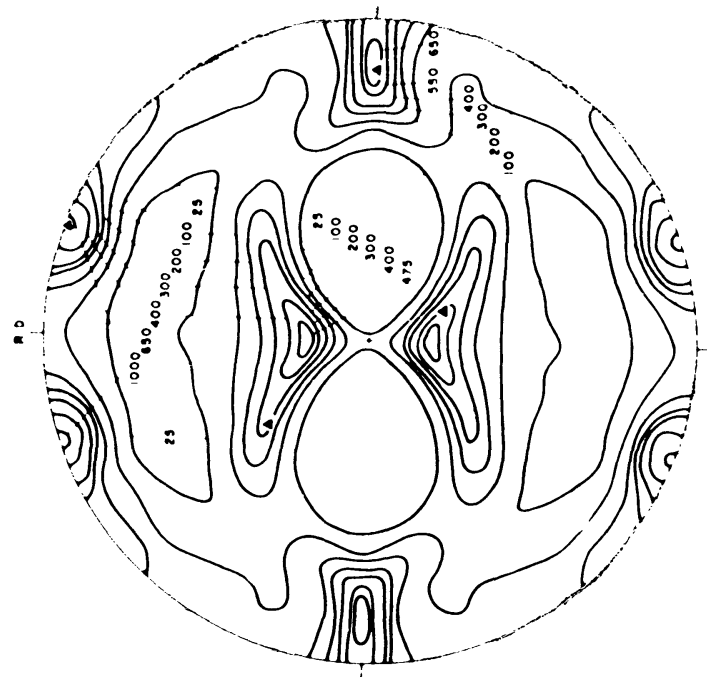

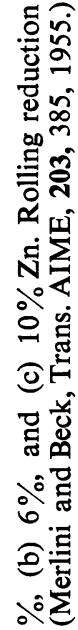

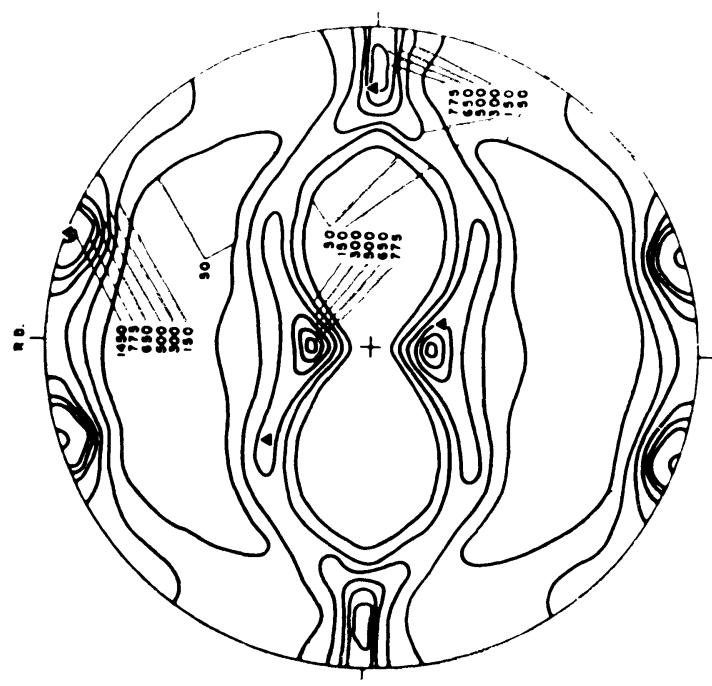

๙

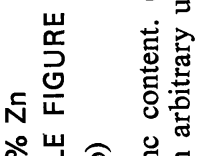
ㅇํㅇㄹㅣ ᄅ. E $\quad$.

을

范

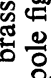

$\Xi$

突

牙

율

的象

N

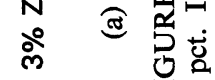

เุ็ 


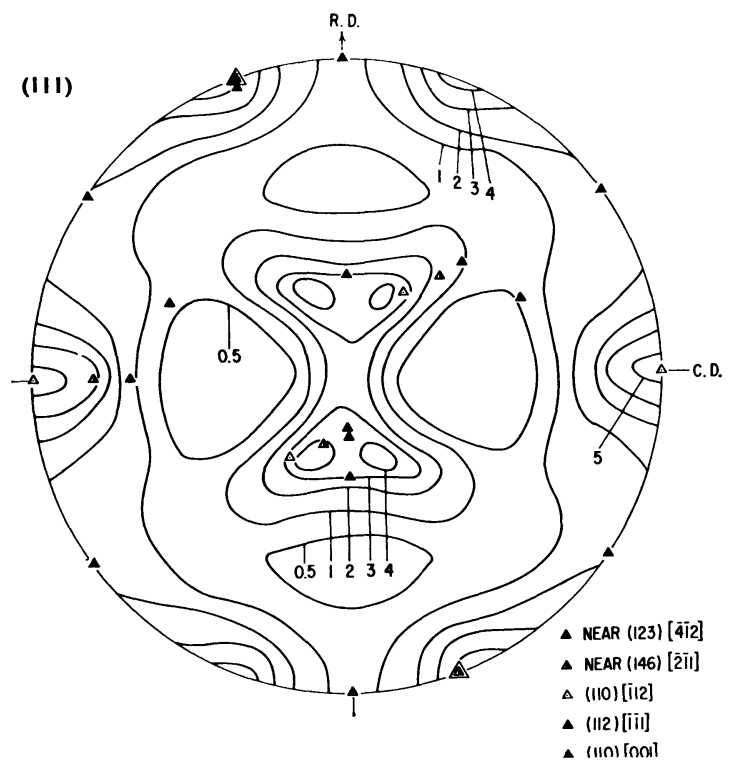

(a)

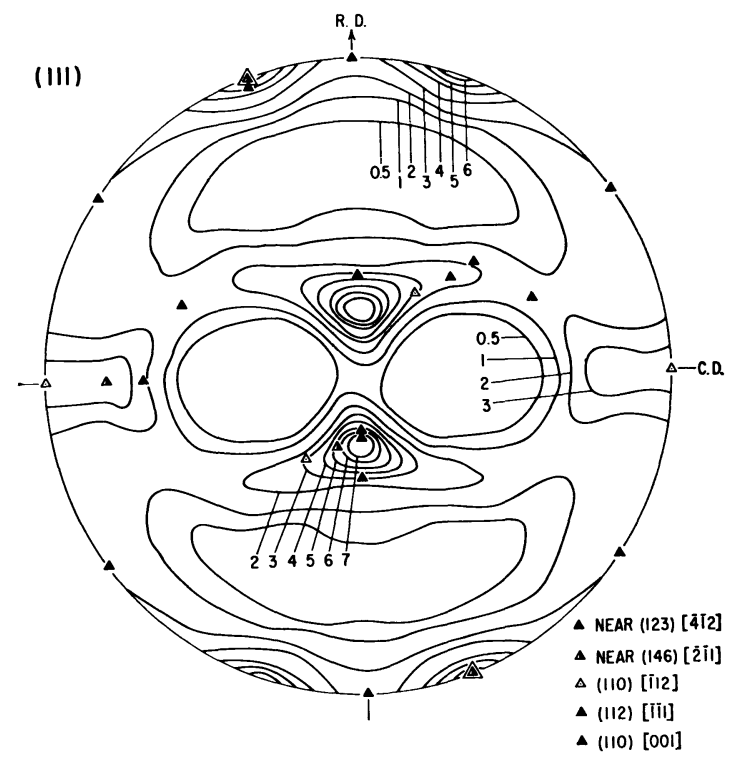

(b)

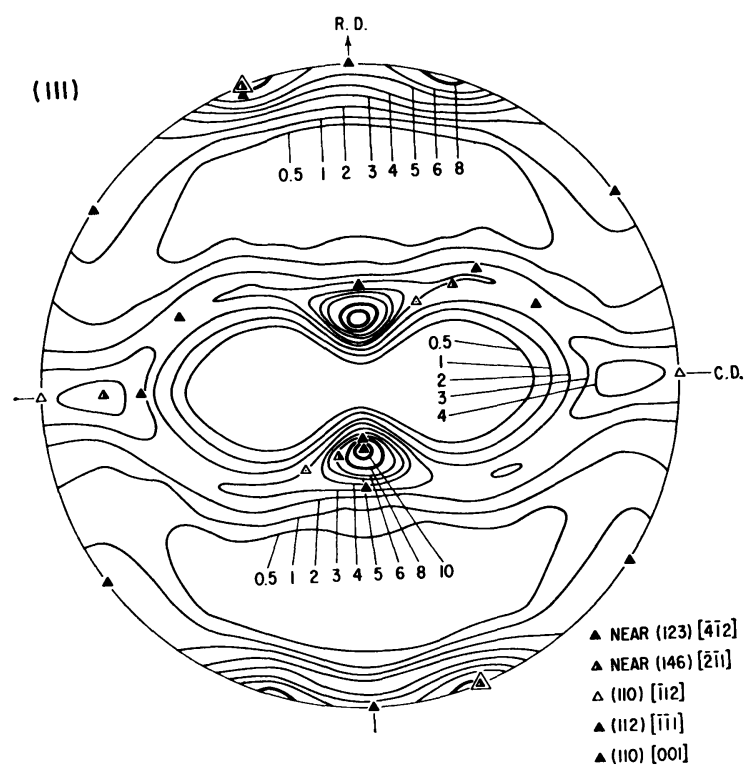

(c)

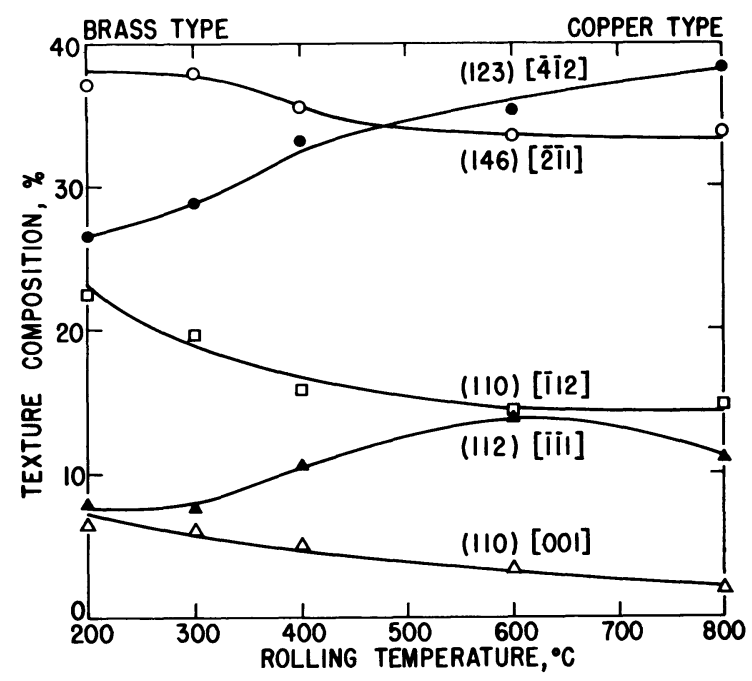

(d)

FIGURE 6 Texture transition in Type 304L stainless steel as a function of deformation temperature. (a) $200^{\circ} \mathrm{C}$, (b) $400^{\circ} \mathrm{C}$, (c) $600^{\circ} \mathrm{C}$, and (d) change in texture composition, based on the intensities from (111) reflections. Rolling reduction 90 pct. (Goodman and Hu, Trans. TMS-AIME, 230, 1413, 1964.) 


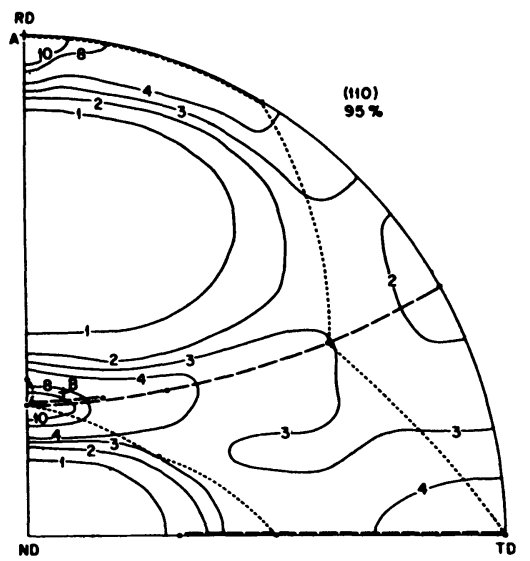

(a)

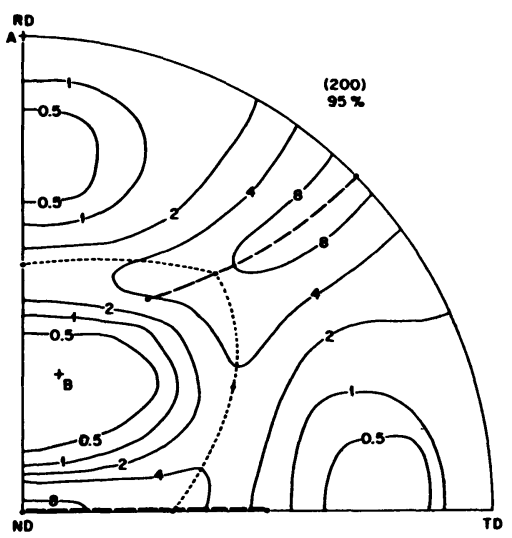

(b)

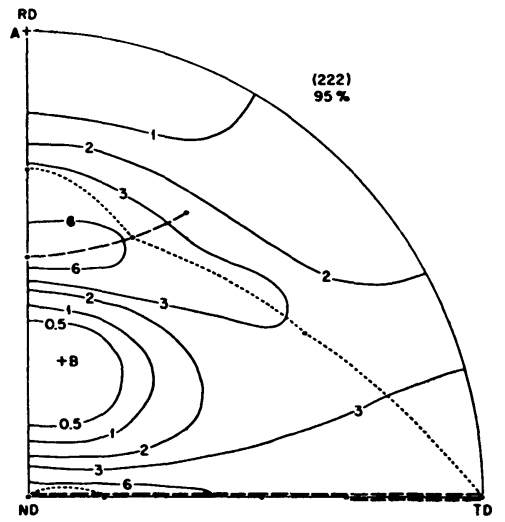

(c)

FIGURE 7 Texture of niobium as shown by (a) (110), (b) (200), and (c) (222) pole figures. Dashed and dotted lines are loci of rotations around axes $A$ and $B$ respectively, indicating the orientation ranges. (Vandermeer and Ogle, Trans. TMS-AIME, 242, 1317, 1968.)

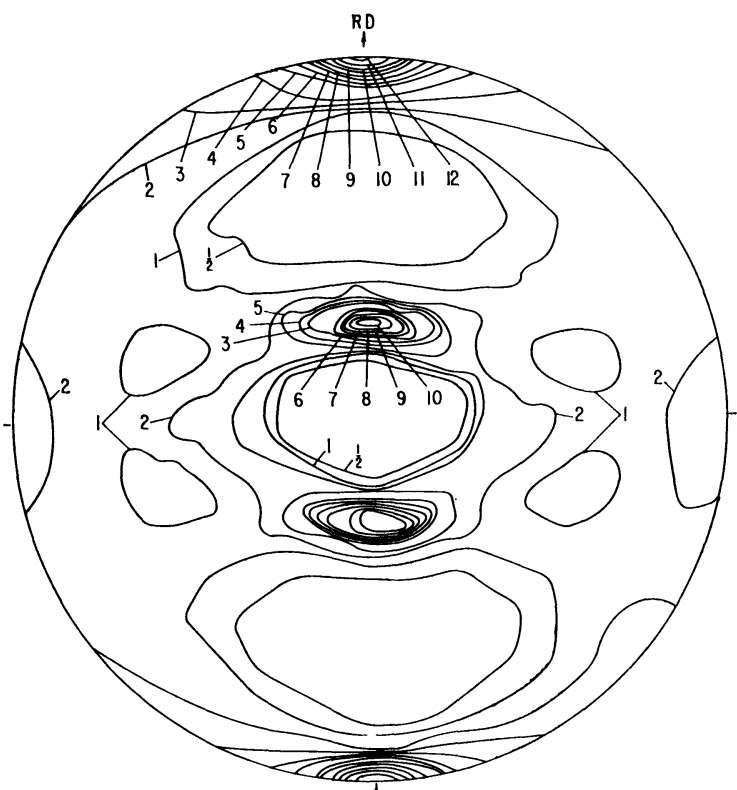

(a)

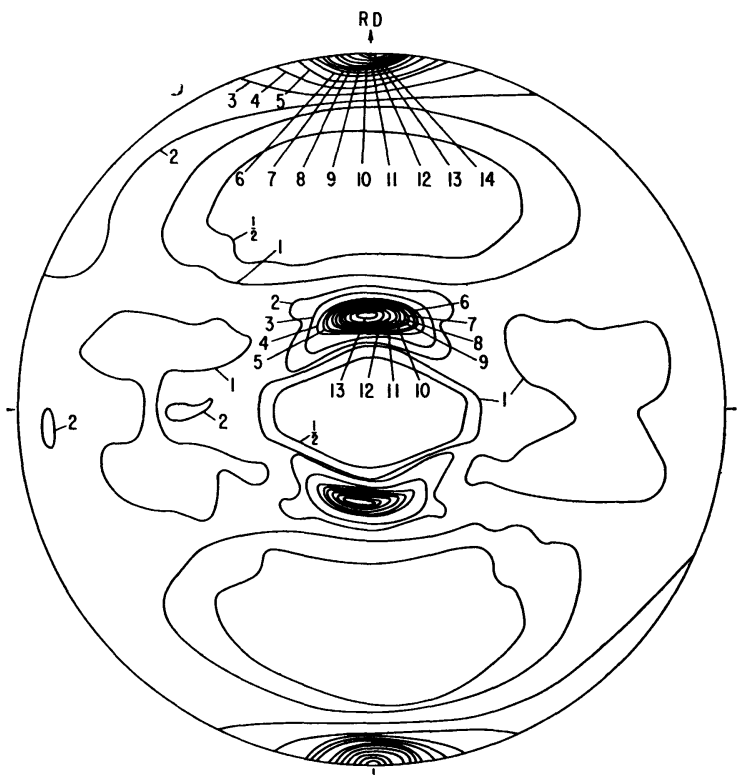

(b)

FIGURE 8 (110) pole figures showing textures of iron and $\mathrm{Fe}-0.8 \% \mathrm{Cu}$ alloy, cold-rolled $90 \mathrm{pct}$ after indicated treatments. (a) Iron, quenched from $925^{\circ} \mathrm{C}$, (b) $\mathrm{Fe}-0.8 \% \mathrm{Cu}$, quenched from $925^{\circ} \mathrm{C}$, reheated to $700^{\circ} \mathrm{C}$, slowly cooled. (Leslie, Trans. TMS-AIME, 221, 752, 1961.) 
The presence of a moderate volume fraction of second-phase precipitates has little influence on the deformation texture. Figure 8 shows the rolling textures of $\mathrm{Fe}$ and an $\mathrm{Fe}-0.8 \% \mathrm{Cu}$ alloy. The latter was solution-treated, then aged before deformation. However, for a similar reason mentioned earlier for patented steel wires, the rolling texture of a eutectoid steel is much weaker than that of mild steels.

The rolling texture of zone-refined $\mathrm{Fe}$ is considerably sharper than that of less pure $\mathrm{Fe}$; the (112) [1101 component is strengthened, whereas the (111)[1112] component weakened. This may be a result of extensive dynamic recovery in iron of zonerefined purity.

In hcp metals the rolling textures can be classified into three categories, according approximately to the $\mathrm{c} / \mathrm{a}$ ratio. For those metals with an axial ratio very close to that for ideal close-packing, $\mathrm{c} / \mathrm{a}=$ 1.633, such as $\mathrm{Mg}$ and $\mathrm{Co}(\mathrm{c} / \mathrm{a}=1.624)$, the rolling texture tends to be (0001) [21̄10], i.e. the basal planes are nearly parallel to the rolling plane, and a closepacked direction in the basal plane coincides approximately with the rolling direction. For metals with $\mathrm{c} / \mathrm{a}>1.633$, such as $\mathrm{Zn}(\mathrm{c} / \mathrm{a}=1.856)$ and $\mathrm{Cd}$ $(\mathrm{c} / \mathrm{a}=1.885)$, the basal planes tend to be tilted 20 to $25^{\circ}$ each way from the rolling plane with the transverse direction as the tilting axis; and a [1010] direction lies in the transverse direction. The rolling textures of hexagonal $\mathrm{Zr}, \mathrm{Ti}, \mathrm{Hf}$, and $\mathrm{Be}$ (with $\mathrm{c} / \mathrm{a}=$ $1.589,1.587,1.581$, and 1.568 respectively), all having low axial ratios, are very similar. In contrast with the rolling textures of those metals with high axial ratios, the basal planes are tilted from the rolling plane with the rolling direction as the tilting axis. The tilt angle varies from 30 to $40^{\circ}$, or even more at very high reductions. A [1010] direction is parallel to the rolling direction. Figure 9 shows the rolling textures of iodide $\mathrm{Ti}$, typical of low $\mathrm{c} / \mathrm{a}$ metals.

Alloy additions, interstitial impurities, and temperature of deformation may affect the nature of the texture, or the degree of orientation spread. Additions of $2 \%$ or more $\mathrm{Al}$, for example, change the rolling texture of $\mathrm{Ti}$ sheet to (0001)[1010]. A change in deformation mechanism or in dynamic recovery during deformation would certainly influence the resulting textures.

Orthorhombic $\alpha$-uranium develops complex rolling textures which vary with the deformation temperature. Cold-rolled U foil has preferred orientations near (102)[010] and (012)[021]. Rolling at higher temperatures produces additional components, which can be described as approximately

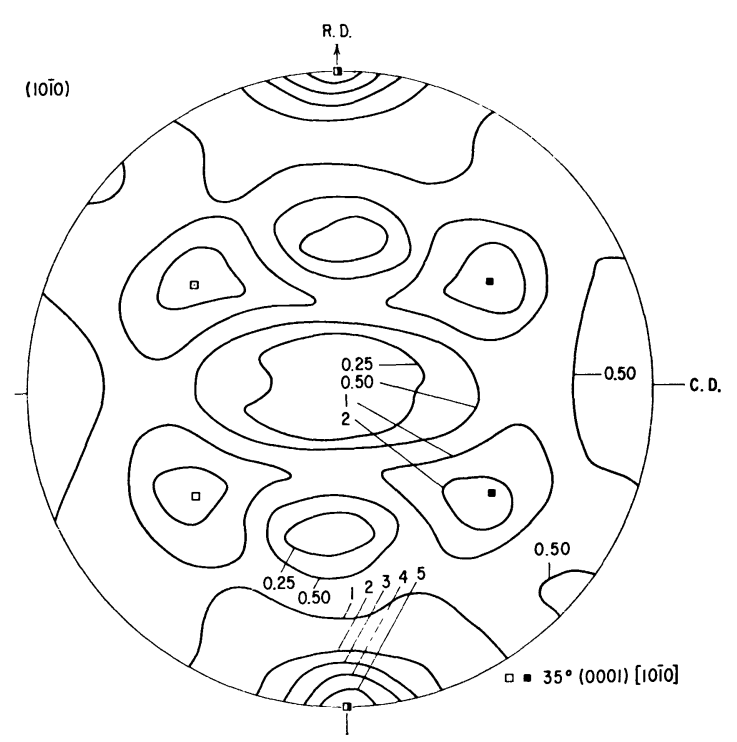

FIGURE 9 Texture of iodide titanium rolled 94 pct at $25^{\circ} \mathrm{C}$. (Hu and Cline, Trans. TMS-AIME, 242, 1013, 1968.)

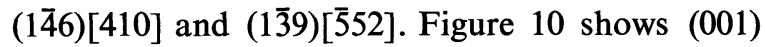
and (110) pole figures for $U$ rolled $87 \%$ at $300^{\circ} \mathrm{C}$. The complexity of $U$ textures arises from the low crystal symmetry of the metal; it deforms by a number of slip and twinning systems that are not crystallographically equivalent.

Surface textures in rolled sheets Just as in wire drawing or in any other forming process, frictional forces between metal and rolls produce surface textures differing from those in the interior of the sheet. Under the same rolling conditions, surface textures produced by unidirectional rolling are more pronounced than those developed by reversed rolling in successive passes. The surface texture, aside from being generally more scattered or less sharp than the interior texture, is frequently related to the interior texture by a rotational displacement with the transverse direction as the rotation axis. In addition to friction, there is evidence that deformation zone geometry plays an important role in causing depth-dependent variations in texture.

Cross-rolling textures Straight-rolled sheet usually exhibits high unequal properties in the longitudinal and transverse directions. Such planar anisotropy can be reduced by cross-rolling. With approximately equal amounts of reduction in two perpendicular directions, a highly symmetrical texture is usually obtained. Among the fcc metals, the crossrolling texture of $\mathrm{Cu}$ is mainly (110)[2吕], plus 


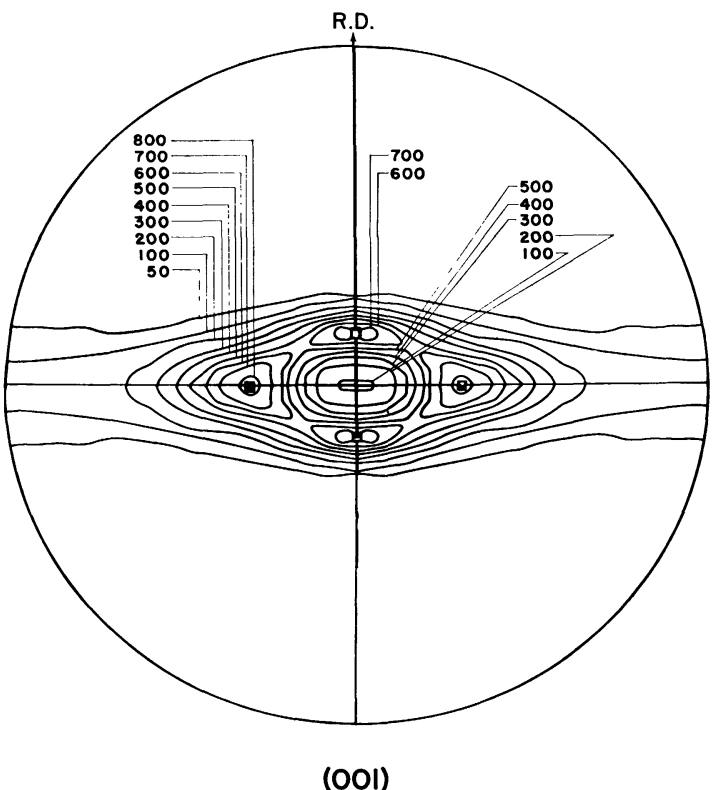

(a)

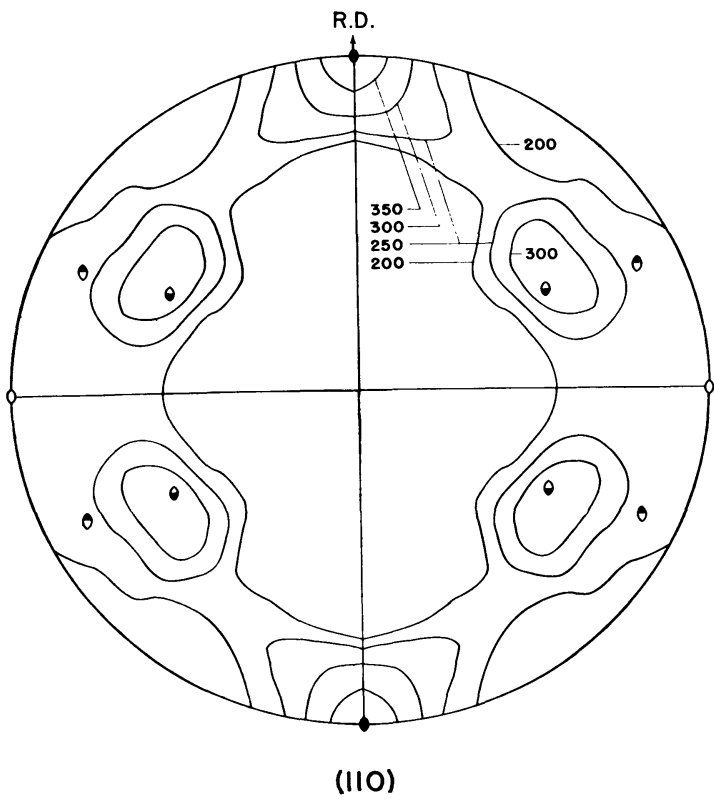

(b)

FIGURE 10 Texture of uranium rolled $87 \mathrm{pct}$ at $300^{\circ} \mathrm{C}$ as shown by (a) (001), and (b) (110) pole figures. Intensity in arbitrary units.

$\sim(146)[410]$

$\sim(139)[352]$

$\sim(103)[010]$ (very close to (102)[010]

$\sim(038)[031]$ (very close to $(0 \overline{1} 2)[021]$

(Mueller, Knott, and Beck, Trans. AIME, 203, 1214, 1955).

minor components related to the cube orientation. The cross-rolling texture of an fcc $\mathrm{Fe}-\mathrm{Ni}$ alloy is similar to that of $\mathrm{Cu}$. In contrast to its straightrolling texture, cross-rolled $70-30$ brass has essentially the same texture as cross-rolled $\mathrm{Cu}$, Figure 11. For bcc metals, such as Fe, low-carbon steel, and Mo, the cross-rolling texture is mainly (100)[011] plus minor components of (111) [ $\overline{2} 11]$ and (111) [1110]. For hcp metals, $\mathrm{Zr}$ has a cross-rolling texture of (0001)[1010] with reference to the first rolling direction, and (0001)[1120] with reference to the second rolling direction. When a hot-pressed $\mathrm{Be}$ plate with random grain orientation is cross-rolled at $870-1000^{\circ} \mathrm{C}$, a (0001) fiber texture is developed, superimposed with (0001)[1010] orientations with reference to either of the two rolling directions.

\section{ANNEALING TEXTURES}

\section{The Annealing Phenomena}

During annealing, the microstructure of a deformed metal undergoes a sequence of changes. According to the structural features, the progress of annealing is commonly described by three consecutive and overlapping stages, i.e., recovery, recrystallization, and grain growth. Recovery involves the annealingout of point defects and the annihilation and rearrangement of dislocations, which leads to the formation of polygonized subgrains. During this stage of annealing, there is essentially no change in texture. If the annealing temperature is sufficiently high, recrystallization occurs by the "nucleation" and growth of new grains, which are essentially perfect and widely different from the polygonized matrix in orientation. These new grains grow at the expense of the matrix by the migration of highangle boundaries. Thus, recrystallization is always accompanied by a large change in orientation in local regions. Grain growth usually refers to the increase of the average grain size upon continued annealing, after recrystallization is complete. In normal or continuous grain growth, i.e., the distribution of grain size remains essentially unchanged during the process, there is usually a gradual evolution of the annealing texture. In abnormal, 


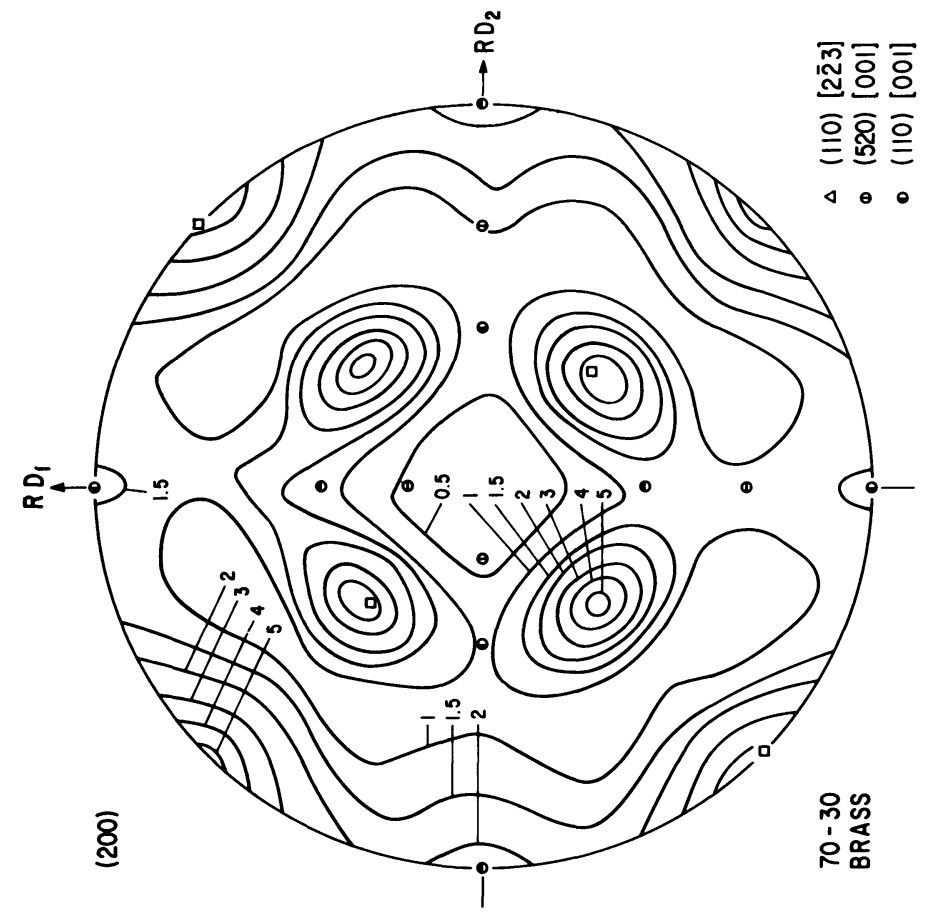

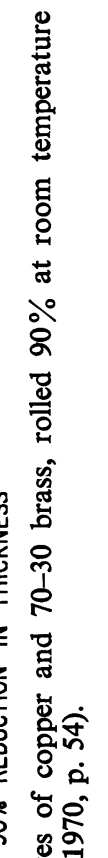

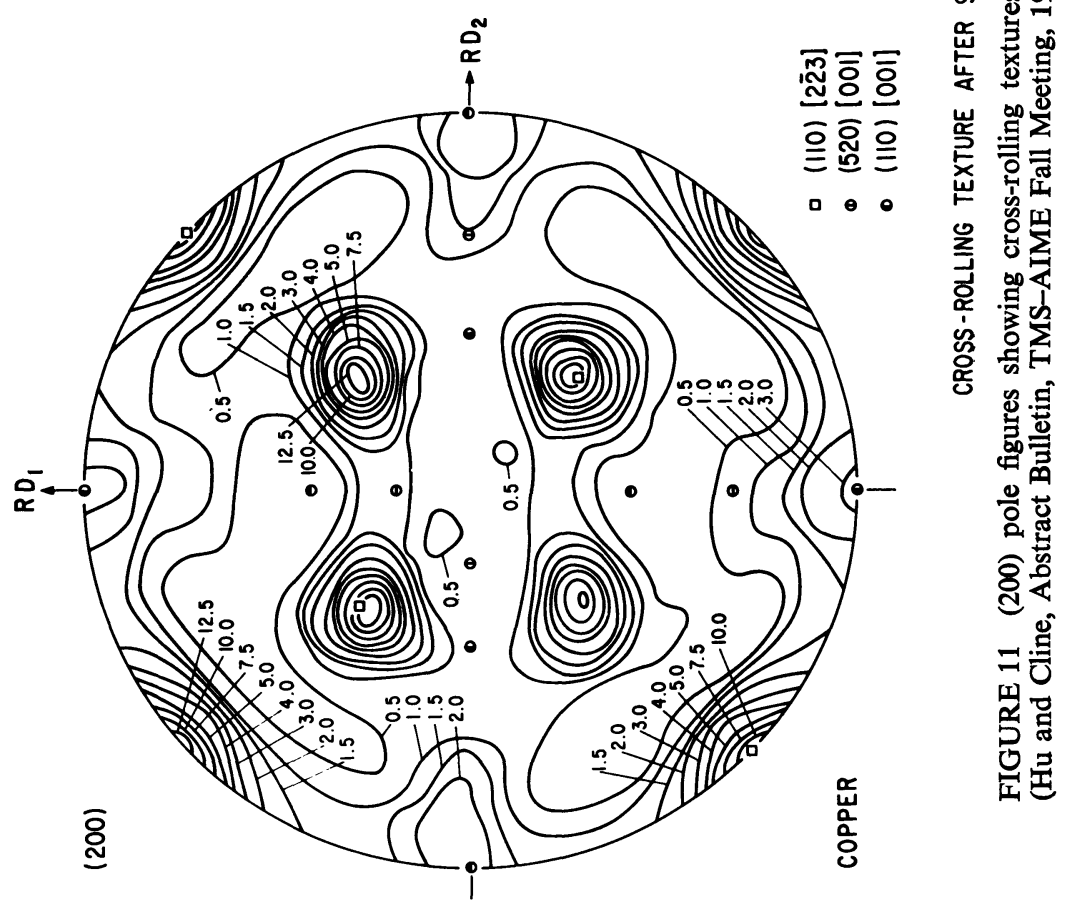


discontinuous, or exaggerated grain growth only a few grains grow to very large size at the expense of the fine-grained matrix and there is a large change in annealing texture. This type of grain growth is also known as secondary recrystallization or grain coarsening, and is usually caused by a finely dispersed second phase, or a strong single-orientation primary recrystallization texture. Either of these conditions can inhibit normal grain growth, but allow a few grains to grow disproportionately. In the absence of these inhibitions, and when the primary grains have grown to a stable size limited by the sheet thickness, coarsening can also occur by the growth of those grains having a low surface (gas-metal interface) energy.

\section{Reorientations in Annealing}

In general, the deformation texture normally determines the recrystallization texture, which, in turn, determines the secondary recrystallization or growth texture. Usually, the new texture is related to its parent texture by rotations around specific crystallographic axes. For example, in fcc metals or alloys, the orientation relationships can be described by [111] rotations of $30-40^{\circ}$, in bcc metals, by [110] rotations of $20-30^{\circ}$; rotational relationships of the [100] type are occasionally observed in addition to these. In hcp metals, reorientations due to recrystallization can be described by [0001] rotations of about $30^{\circ}$, and by approximately [1010] rotations of $90^{\circ}$. These orientation relationships correspond to high rates of growth of the recrystallized grains. It is well known that grain boundary mobility depends on orientation.

However, exceptions may arise from unidentified complications. Annealing textures are sensitive to many factors. For a given material, the thermal or mechanical history of the specimen, the conditions of the final anneal (the temperature, the heating rate, the furnace atmosphere, the application of stress during annealing, etc.), and the presence of minor impurities may substantially influence the annealing textures.

Two main theories have been proposed for the formation of recrystallization textures. One of these suggests that the recrystallization texture is determined by the orientations of the nuclei formed (the oriented-nucleation mechanism), and the other, by the orientation-dependence of the rate of growth of the nuclei (the oriented-growth mechanism). We shall not discuss these theories further.

\section{Annealing Textures of Wires or Rods}

Various recrystallization textures have been reported for fcc wires or rods. The discrepancies may result from differences in material composition, the amount of cold work, the progress of annealing, or the techniques of texture measurements. Available data indicate that heavily drawn wires with a single fiber texture tend to retain their deformation texture upon recrystallization at a low temperature. This appears to be true for $\mathrm{Al}$, most bcc metals, and hcp Be. Such apparent "retention" of the deformation texture is not necessarily indicative of absence of reorientation upon recrystallization, for reorientation involving rotations around the fiber axis would produce no detectable change in the over-all texture. Annealing at higher temperatures produces new textures, which may be a result of grain growth or secondary recrystallization. Reorientations involving the same type of rotations, but around an axis inclined to the fiber axis, would produce orientations differing from the parent fiber texture. Some of the reported results may be interpreted in this manner. However, this kind of reorientation would not produce a unique new fiber texture from a parent texture that is ideally fibrous (i.e. crystals are oriented at random around the fiber axis); the new crystals would have a wide variety of crystallographic axes aligned with the wire or rod axis.

For drawn wires or extruded rods with a duplex fiber texture, annealing at a low temperature may enhance one component at the expense of the other, because of differences in the stored energy or in the rate of recovery. Reorientation may occur within each component as a result of recrystallization or subsequent coarsening.

Table IV summarizes the annealing textures in wires or rods of various metals and alloys.

\section{Annealing Textures of Tubes}

To a first approximation, the development of annealing textures in deformed tubes is frequently similar to that in wires or rods, or in rolled sheets, depending on the nature of the deformation texture of the tube. For copper or brass tubes, cold-rolled or drawn with approximately equal reductions of diameter and wall thickness, the $[111]+[100]$ duplex fiber texture is retained, but somewhat scattered, upon annealing. Cold-formed tubes of $\mathrm{Zr}$ or Zircaloy having [1010] parallel to the tube axis, tend to develop a [11 20$]$ texture upon anneal- 


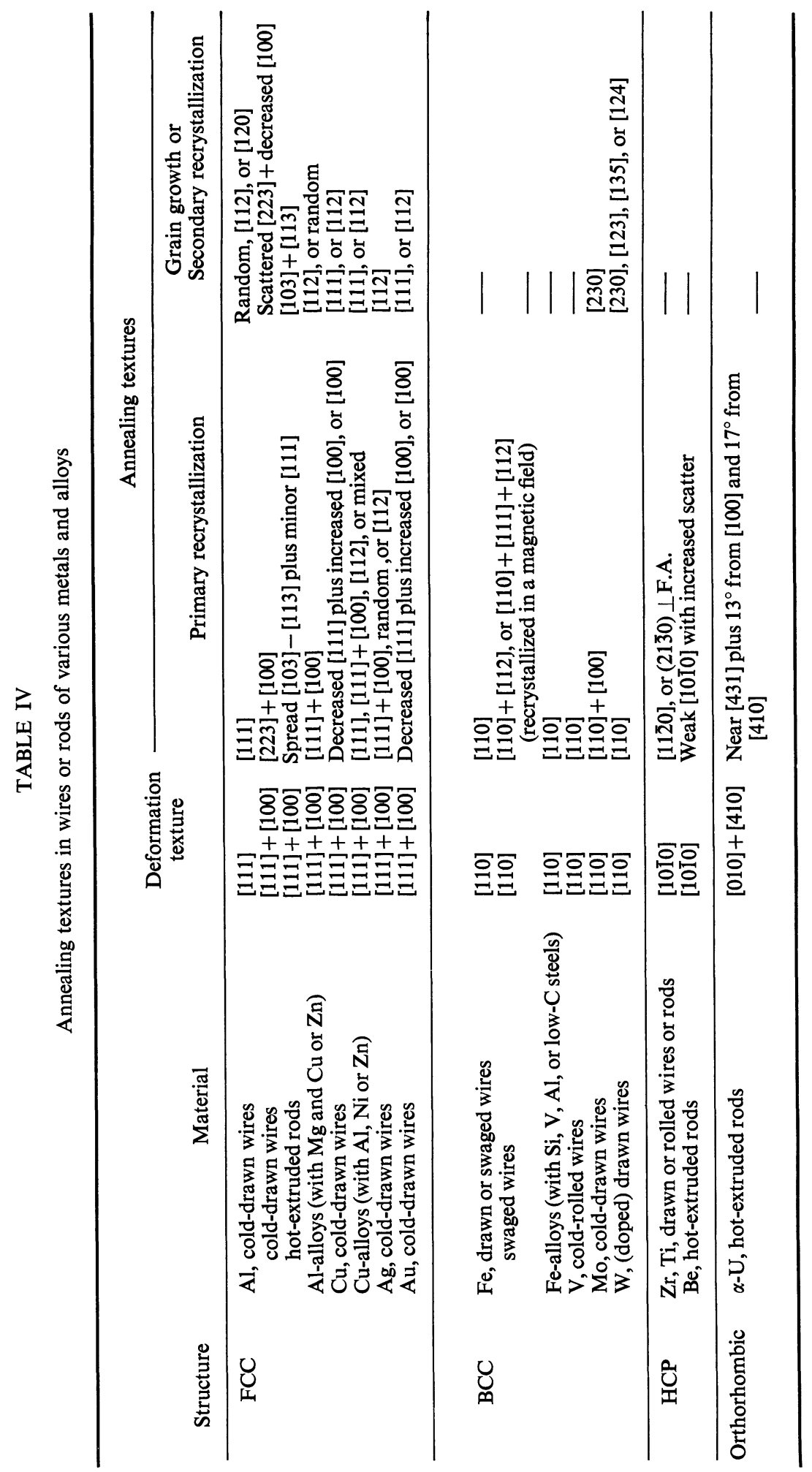


ing. Beryllium tubes with a fully recrystallized structure after hot extrusion have a [1010] texture.

\section{Annealing Textures of Compression Specimens}

Compression-rolled aluminum largely retains its deformation texture upon recrystallization, although local reorientations due to the formation of new grains are evident. Secondary recrystallization in compression-rolled aluminum and silver produces [111] and [110] textures respectively.

Recrystallization of compression-deformed iron and decarburized mild steel tends to retain the major deformation texture component [111], and to lose the minor component [100]. Compressionrolled Mo retains its deformation texture after recrystallization.

\section{Annealing Textures of Rolled Sheets}

In fcc metals, textures resulting from recrystallization can have a remarkably sharp (100)[001] orientation-the so-called cube texture-or a combination of other types of orientations entirely different from the cube orientation, depending upon the deformation texture. In general, if the rolling texture is of the copper-type, cube texture is produced by recrystallization. Usually there is a minor component of (122)[215] orientation, which arises from annealing twins of the cube grains. Figure 12 shows cube texture in a heavily rolled, then recrystallized $\mathrm{Cu}$ sheet. A fully developed cube texture may approach the perfection of a pseudosingle crystal. Conditions favoring the development of a sharp cube texture are: (1) a small penultimate grain size, (2) a heavy total reduction, and (3) a high annealing temperature. The cube texture is related to the copper-type rolling texture by [111] rotations of about $40^{\circ}$.

The copper-type rolling texture may be retained after recrystallization in a few exceptional cases, such as $\mathrm{Cu}-1 \% \mathrm{Be}, \mathrm{Ni}_{3} \mathrm{Mn}$, and others. It may also be partially retained, together with a cube texture component, as in Al or Ni of low purity. The retention of the deformation texture upon recrystallization in most of these cases is not entirely a result of recrystallization in situ; it involves local reorientations of such a nature that the recrystallized grain orientations are the same as a component of the deformation texture (e.g. recrystallized grains formed in the deformation band $A$ have the orientation of the deformation band $B$, and vice versa). These exceptions are mostly a consequence of

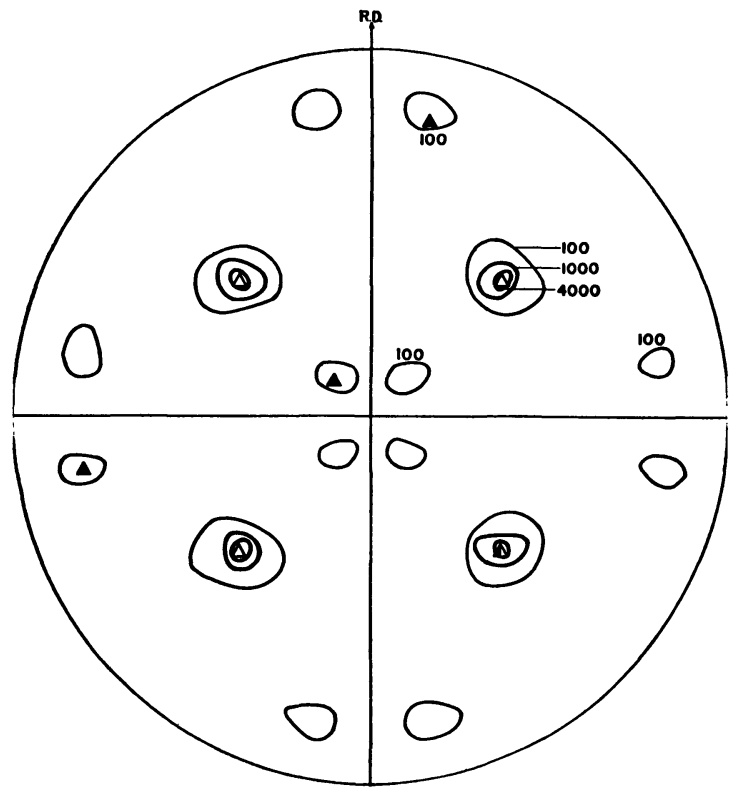

(a)

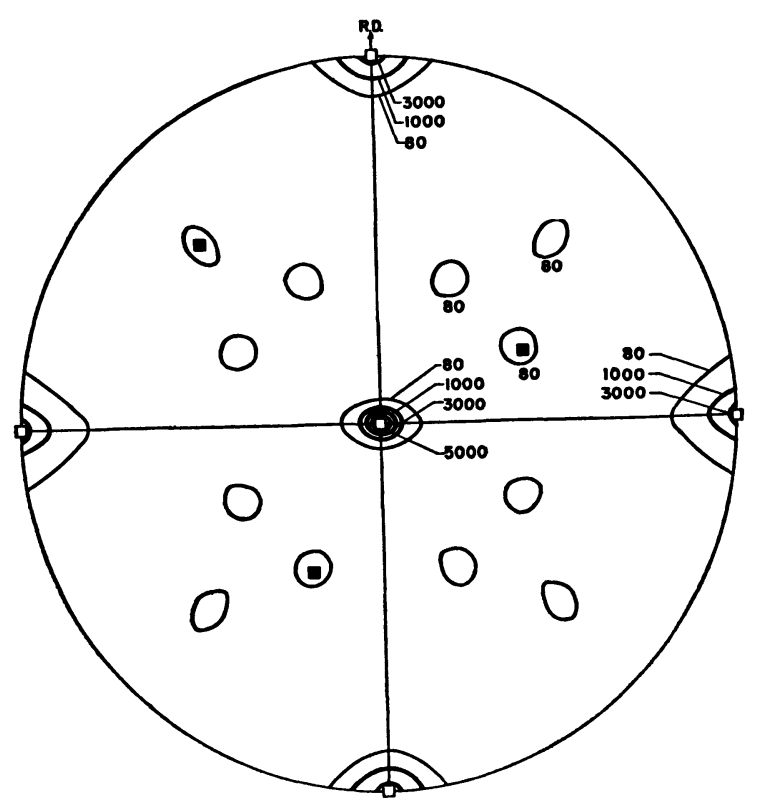

(b)

FIGURE 12 Recrystallization texture of electrolytic tough-pitch copper, rolled 96 pct and annealed $5 \mathrm{~min}$ at $200^{\circ} \mathrm{C}$, as shown by (a) (111), and (b) (200) pole figures. Intensity in arbitrary units.
$\triangle \square(100)[001]$

$\triangle$ (122)[212]

(Beck and Hu, Trans. AIME, 194, 83, 1952.) 
inhibited growth of cube grains caused by solute impurities or finely dispersed precipitates; the annealing textures of these materials are usually sensitive to the prior thermal or mechanical history of the specimen.

Cube texture in fcc metals has been a subject of great interest, not only for scientific value, but also for its industrial importance. It has long been known that earing in cup-drawing is associated with the texture of the sheet, and that cube texture gives ears at $0^{\circ}$ and $90^{\circ}$ to the rolling direction. Cube texture in $\mathrm{Fe}-\mathrm{Ni}$ alloys (Permalloy) has been utilized to advantage in magnetic applications.

For those fcc metals or alloys whose rolling textures are of the silver-type, such as Ag, $\alpha$-brass and some other $\mathrm{Cu}$ alloys, the recrystallization textures are considerably more complex than the simple cube texture. Figure 13 shows the texture of an almost completely recrystallized specimen of common silver. In these pole figures, various ideal orientations frequently found in the silver-type recrystallization textures are indicated for comparison. For example, in high-purity $\mathrm{Ag}$, the approximate $(120)[\overline{2} 11]$ orientation is the most prominent, whereas in $70-30$ brass, the (225)[ $\overline{7} \overline{3} 4]$ or (113) $[\overline{2} \overline{1} 1]$ is predominant. Thus, the silver-type recrystallization textures, although usually having essential features in common, differ appreciably in detail, depending on material and on purity. In spite of these differences, the recrystallization textures are related to the deformation texture by [111] rotations of about 30 or $35^{\circ}$ in each case, only the selection of a particular [111] as the rotation axis being different. The reason for such a different behavior in reorientation is not clear. However, in no case is the location of the intensity maxima of the silver-type rolling textures exactly on (110)[1112], and the deviations from the exact (110)[112] orientation vary from metal to metal, or with the purity of the same metal.

For those metals or alloys whose rolling textures are intermediate between the copper-type and the silver-type, such as those produced either by alloy additions or by varying the deformation temperature in texture transition, the recrystallization textures are correspondingly a mixture of the cube orientation and those orientations characteristic of the silver-type recrystallization texture. Figure 14 shows the recrystallization textures of $\mathrm{Cu}$ rolled at $-140^{\circ}$ and $-196^{\circ} \mathrm{C}$, then annealed $15 \mathrm{~min}$ at $400^{\circ} \mathrm{C}$ for complete recrystallization. The prior rolling textures of these specimens are quite similar to those of $6 \%$ and $10 \% \mathrm{Zn}$ brasses shown earlier

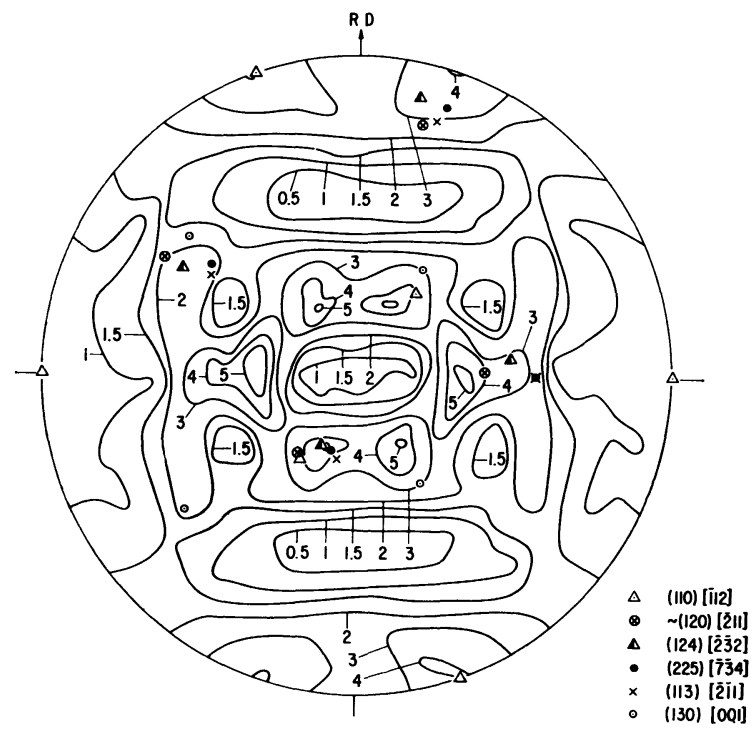

(a)

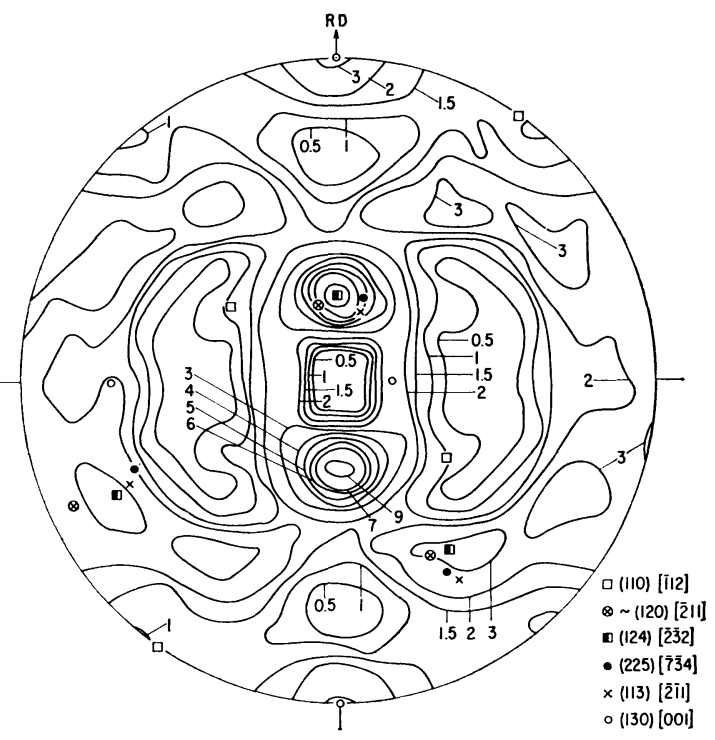

(b)

FIGURE 13 Texture of an almost completely recrystallized specimen of common silver ( 99.99 pct pure) rolled 91 pct at $0^{\circ} \mathrm{C}$ and annealed $15 \mathrm{~min}$ at $200^{\circ} \mathrm{C}$. The (110)[112] orientation represents the residual deformation texture. (a) (111), and (b) (200) pole figures. (Hu, Cline and Goodman Trans TMS-AIME, 224, 96, 1962.) 
in Figure 5, and so are their corresponding recrystallization textures.

The alloys of $\mathrm{Cu}$ with a high solute content of $\mathrm{P}$, $\mathrm{As}$, or Sb (Subgroup V-B elements) appear to be exceptional cases. From a silver-type rolling texture, the major components of the recrystallization textures of these alloys are not related to the (110)[112]-type deformation texture by [111] rotations, but by rotations around the sheet-plane normal, which is a [110] axis.

Secondary recrystallization or grain coarsening, occurs in fcc metals or alloys with cube texture during annealing at a high temperature. In these cases, normal growth of the primary grains is impeded by the very low mobility of their boundaries, since they are mostly of low-angle disorientations. Thus, only a few sufficiently offoriented grains are able to grow. However, if the cube texture is highly perfect, secondary recrystallization may be very difficult because of the lack of secondary "nuclei" among the primary grains. In silver or $\alpha$-brass, grain coarsening usually occurs in a more or less gradual manner. These structural changes are always accompanied by a change in texture, and the new textures are usually related to the primary recrystallization textures by [111] rotations of 30 to $40^{\circ}$ in a direction opposite to that occurring during primary recrystallization. Thus, the nature of secondary-recrystallization textures is essentially similar to that of the corresponding deformation textures. Secondary grains formed in thin sheets of pure Pt upon annealing at a high temperature have (111) orientation, as the surface energy of these grains is the lowest.

In bcc metals or alloys, the recrystallization textures are largely similar, although the relative prominence of the various texture components may differ to some extent, because of material or processing variations. In heavily rolled $\mathrm{Fe}$, the evolution of annealing textures may be described as follows: (1) there is little change in texture when primary recrystallization is complete; (2) as grain growth progresses, the (100)[011] deformation texture component gradually disappears and a partial fiber component with a [110] fiber axis inclined at about $30^{\circ}$ to the sheet-plane normal and toward the rolling direction emerges; and (3) further annealing leads to the development of (111)[110] and (112)[110] textures. Pole figures representing these features are shown in Figure 15. Prolonged annealing at $700^{\circ} \mathrm{C}$ may produce a secondaryrecrystallization texture of $\sim(554)[\overline{2} \overline{2} 5]$ orientation,

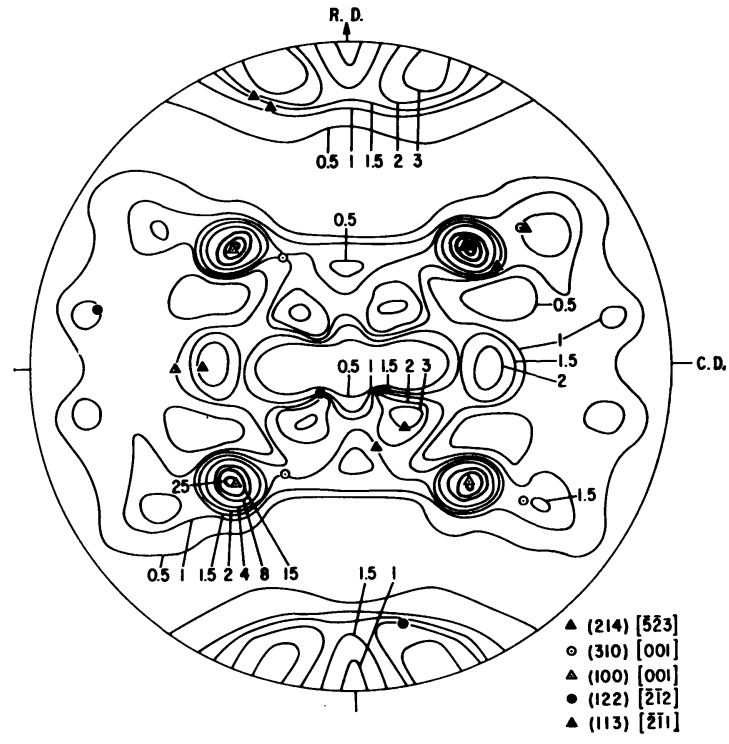

(a)

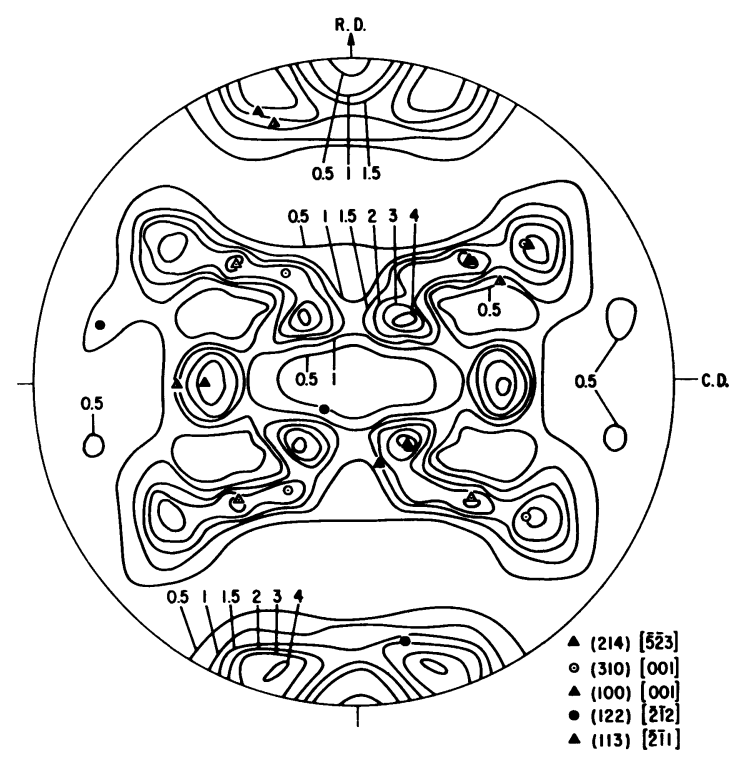

(b)

FIGURE 14 (111) pole figures showing the recrystallization texture of electrolytic copper, rolled 96.6 pct at (a) $-140^{\circ} \mathrm{C}$, and (b) $-196^{\circ} \mathrm{C}$, then annealed at $400^{\circ} \mathrm{C}$ for 15 min. (Hu and Goodman, Trans. TMS-AIME, 227, 627, 1963. 
which is very close $\left(<6^{\circ}\right)$ to $(111)[\overline{1} 12]$. All these orientational changes can be described as [110] rotations of $20-35^{\circ}$ around the fiber axes. Rolled Mo, which behaves similarly to compression-rolled specimens, retains its deformation texture with some sharpening upon recrystallization.

The stepped-up interest in texture development in low-C steels has been associated mainly with drawability improvement through texture control in rimmed or killed steels. It is known that the Young's modulus of iron single crystals depends on the crystallographic direction, being highest in the

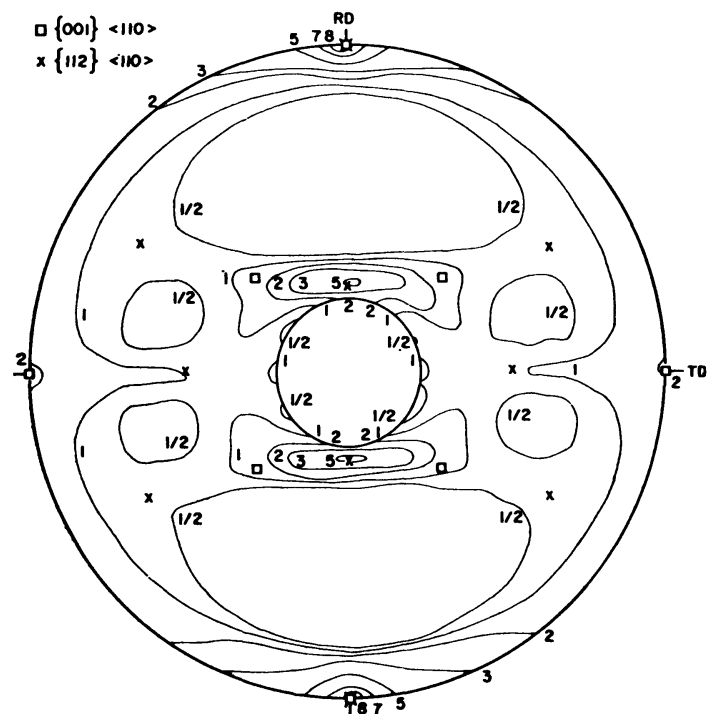

(a)

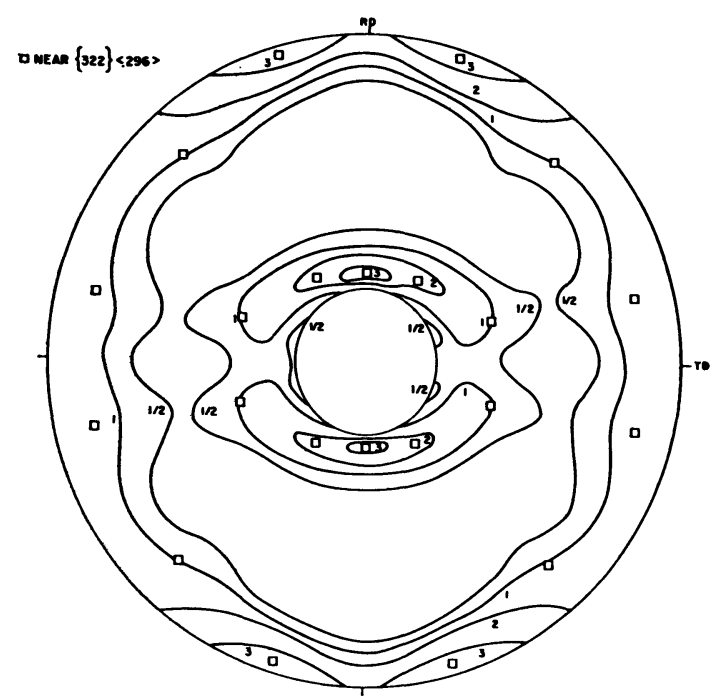

(b)

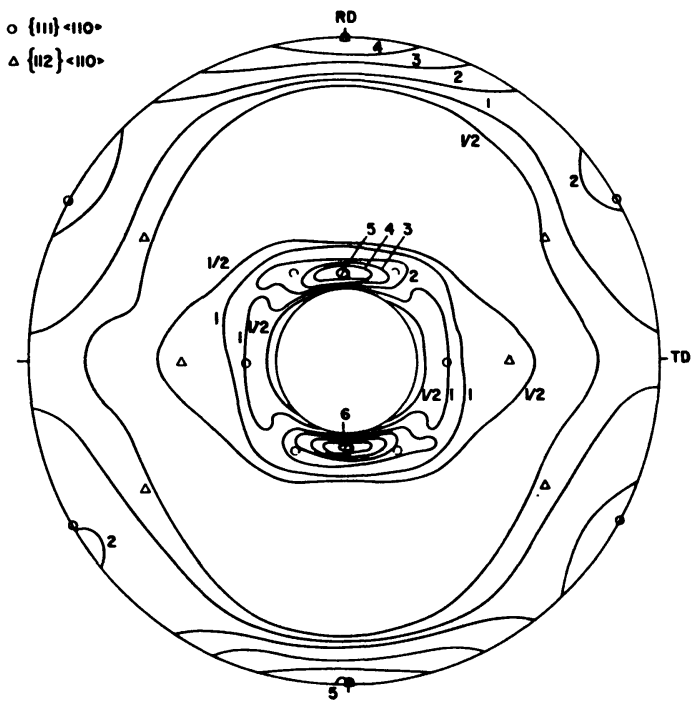

(c)

FIGURE 15 (110) pole figures showing annealing textures of electrolytic iron rolled 90 pct and annealed (a) $1 \mathrm{hr}$ at $500^{\circ} \mathrm{C}$, (b) $10 \mathrm{~min}$ at $700^{\circ} \mathrm{C}$, and (c) $16 \mathrm{hr}$ at $700^{\circ} \mathrm{C}$. (Stickels, Trans. TMS-AIME, 233, 1550, 1965.)

$\langle 111\rangle$, lowest in the $\langle 100\rangle$, and intermediate in the $\langle 110\rangle$ directions. A piece of textured steel would have similar crystallographic anisotropies. For deep-drawing applications, it is necessary that the sheet has a high resistance to thinning (anisotropic in the normal direction), while plastic flow in the plane of the sheet occurs with ease in all directions (isotropic in the plane). Parameters commonly used for indicating these properties are the plastic strain ratio, $r$, which measures the normal anisotropy, and $\Delta r$, which measures the planar anisotropy. They are defined as $r=\varepsilon_{w} / \varepsilon_{t}$ and $\Delta r=\left(r_{0}+r_{90}-2 r_{45}\right) / 2$, where $\varepsilon_{w}$ and $\varepsilon_{t}$ are true strains in the width and thickness directions, respectively, in a uniaxial tension test; the subscript numbers denote the angles between the rolling and the testing directions. The average plastic strain ratio is usually expressed as $\bar{r}=\left(r_{0}+2 r_{45}+r_{90}\right) / 4$. It has been established, both experimentally and theoretically, that a (111) fiber texture with the sheet-plane normal as the fiber axis would be most desirable for deep-drawing, because it would give an optimum $r$, and minimal $\Delta r$ values.

Aluminum-killed steels known for their good drawing properties when processed properly, 
develop recrystallization textures containing

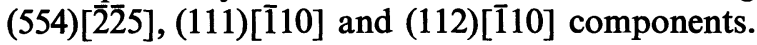
A (200) pole figure indicating such preferred orientations is shown in Figure 16(a). Successful development of this texture depends critically on the pre-precipitation clustering of $\mathrm{Al}$ and $\mathrm{N}$ in the late stages of recovery, which enhances the formation of recrystallized grains with (111) orientations. When $\mathrm{Al}$ and $\mathrm{N}$ are largely precipitated as $\mathrm{AlN}$ prior to cold rolling, the recrystallization texture deteriorates by a reduction of the desirable (111) [1110] component, and by an increase in the un- sensitive to compositional and processing variables. Additions or depletions of certain elements in low concentrations may influence the annealing texture considerably for a given process. Variations of the thermal or mechanical treatments for a given steel may change the final annealing texture substantially. Factors favoring the development of an annealing texture desirable for deep-drawing are: (1) a high hot-rolling finishing temperature (above $A_{3}$ ), (2) a reasonably fast cooling rate (low coiling temperature), (3) a moderately high cold-rolling reduction, (4) a reasonably slow heating rate in the

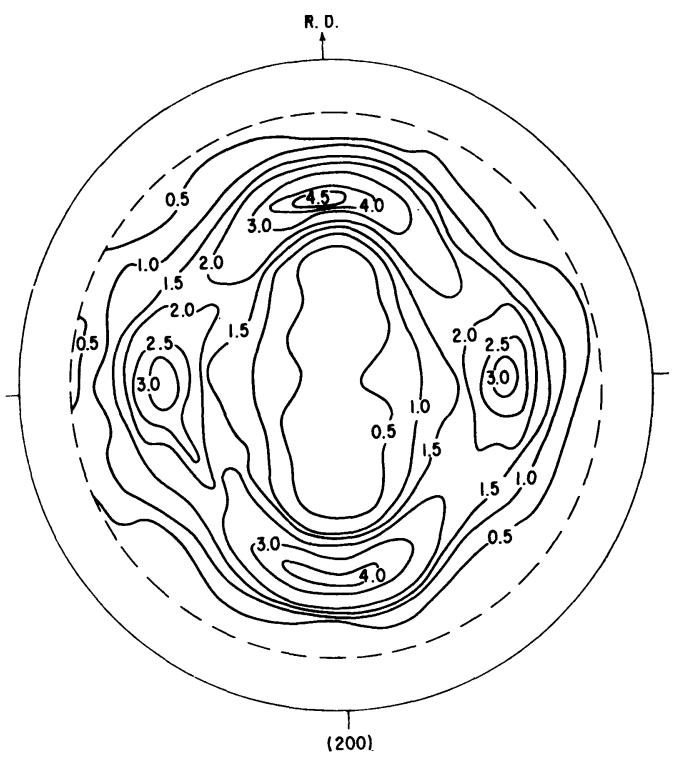

(a)

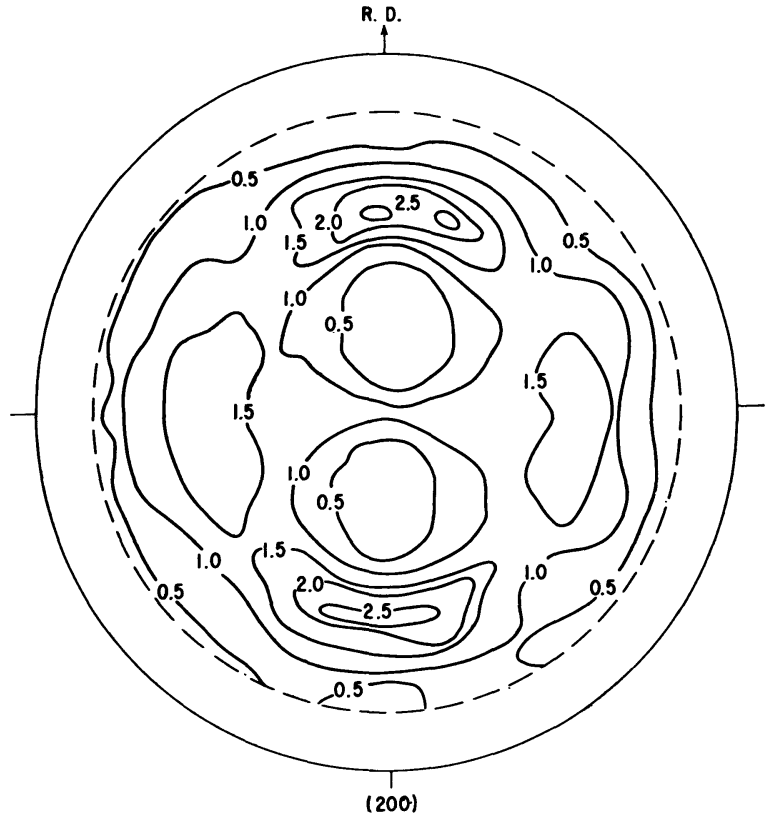

(b)

FIGURE 16 Recrystallization textures of aluminum-killed steels (a) hot-rolled, cold-rolled 65 pct, then annealed at $20^{\circ} \mathrm{C} / \mathrm{hr}$ to $690^{\circ} \mathrm{C}$ (pancake-shaped grains); (b) hot-rolled, annealed $3.5 \mathrm{hr}$ at $705^{\circ} \mathrm{C}$, cold-rolled $65 \mathrm{pct}$, then annealed at $20^{\circ} \mathrm{C} / \mathrm{hr}$ to $690^{\circ} \mathrm{C}$ (equiaxed grains). (Michalak and Schoone, Trans. TMS-AIME, 242, 1149, 1968.)

desirable (100)[011] and other scattered orientations, as shown in Figure 16(b). Aluminum-killed steels of deep-drawing quality are characterized by pancakeshaped grains. However, it is the crystallographic orientation, not the geometric shape, of the grains that is responsible for the anisotrpoic mechanical properties.

Much of recent work in this area has been on texture development in rimmed or unkilled steels. The annealing texture in such steels is highly final anneal, and (5) a suitable soaking period to allow some grain growth. Annealing in a decarburizing atmosphere or the addition of $\mathrm{Ti}$ or $\mathrm{Nb}$ to combine with $\mathrm{C}$ and $\mathrm{N}$ allow the use of higher annealing temperatures for grain growth without phase transformation, and hence, can further improve the texture. Considerable effort has very recently been directed to the development of high strength steel sheets having also good deep drawing capabilities. 

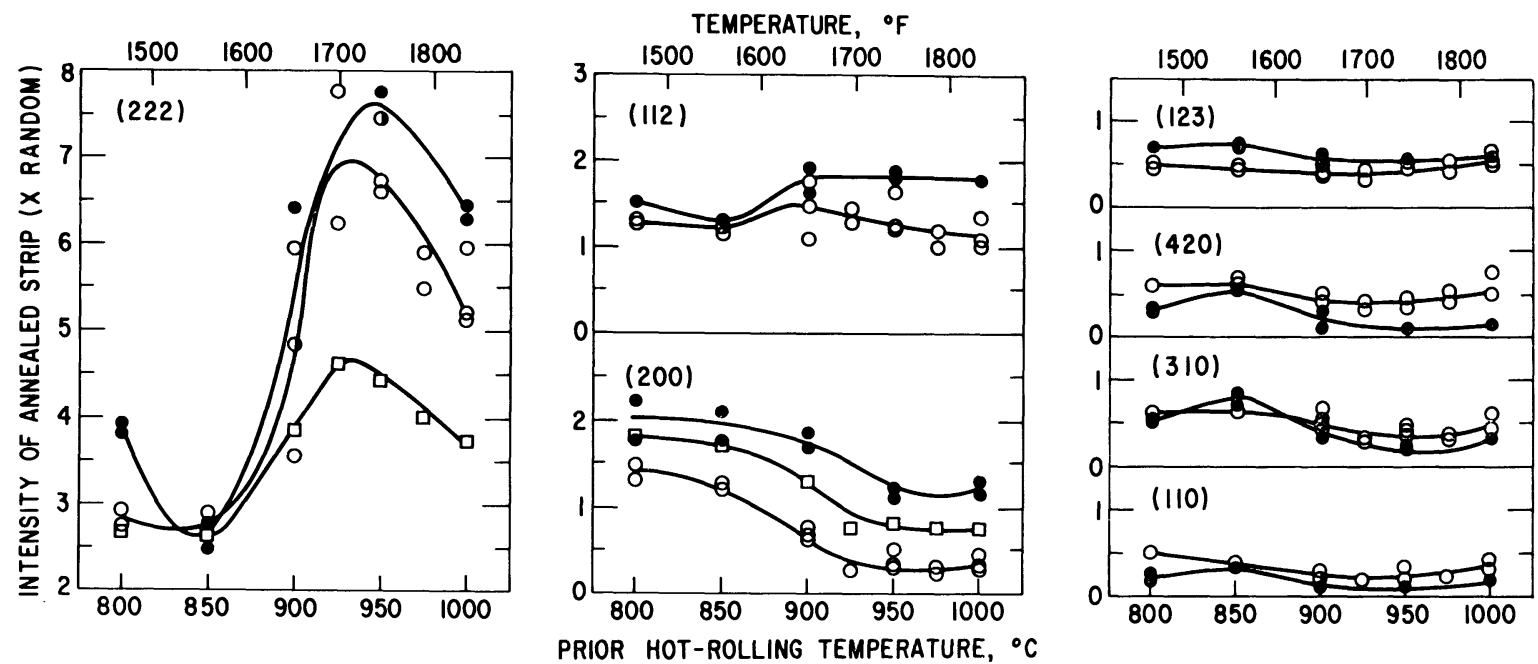

FIGURE 17 Effect of hot-rolling temperature on the annealing textures of a continuously cast low-carbon steel (open symbols), and a vacuum-melted $\mathrm{Fe}-\mathrm{C}$ alloy of comparable carbon content (filled symbols). Specimens were hot-rolled, cold-rolled $70 \mathrm{pct}$, then annealed in dry hydrogen as indicated: Circles, $30 \mathrm{hr}$ to $710^{\circ} \mathrm{C}, 20 \mathrm{hr}$ at $710^{\circ} \mathrm{C}$; squares, $29 \mathrm{hr}$ to $695^{\circ} \mathrm{C}$. (Goodman and Hu, Met. Trans., 1, 1629, 1970.)

Figure 17 shows the effect of hot-rolling temperature on the annealing textures of a continuously cast low-C steel and a vacuum-melted $\mathrm{Fe}-\mathrm{C}$ alloy of comparable $\mathrm{C}$ content. Those specimens, having high (222) and low (200) intensities, had high $r$ values. The effect of $\mathrm{Mn}$ on $\bar{r}$ value is shown in Figure 18.

Among the bcc metals and alloys, secondary recrystallization textures in $\mathrm{Fe}-\mathrm{Si}$ sheets have been studied most extensively. The so-called "cube-on-

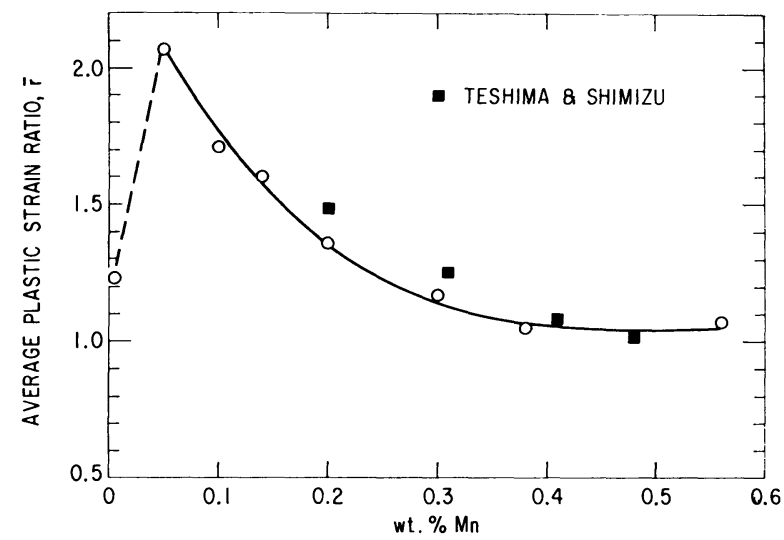

FIGURE 18 Effect of manganese on the average plastic strain ratio, $\bar{r}$, of low-carbon steels, cold-rolled 70 pct, then annealed in $\mathrm{N}_{2}+6 \% \mathrm{H}_{2}$ with a heating rate of $20^{\circ} \mathrm{C}$ per hr to $710^{\circ} \mathrm{C}$ and held at $710^{\circ} \mathrm{C}$ for $20 \mathrm{hr}$. (Hu and Goodman, Met. Trans., 1, 3057, 1970.) edge" orientation, i.e. (110)[001], or the Goss texture, in commercial grain-oriented Si-steels is produced by secondary recrystallization. Usually a two-stage cold rolling and annealing process is employed to obtain the desired thickness. The recrystallized and decarburized sheet is finally annealed at a high temperature in dry hydrogen to effect secondary recrystallization and further purification. Goss-textured Si-steel sheet has been used extensively for power-transformer cores, because of high magnetic permeability in the [001] direction, and hence low energy losses.

The development of Goss texture in Si-steels depends critically on second-phase dispersion during secondary recrystallization. Generally, $\mathrm{MnS}$ is believed to be responsible. Other secondphase inhibitors, such as TiC or TiS, $\mathrm{Si}_{3} \mathrm{~N}_{4}$ or $\mathrm{SiO}_{2}$, and $\mathrm{VC}$ or $\mathrm{VN}$, can affect similar results, although the required temperatures for secondary recrystallization differ: More recent developments of very high permeability and low core-loss Si-steels have made use of AlN, in addition to $\mathrm{MnS}$, for the control of texture to within a few degrees of the (110) [001] orientation.

In the absence of these grain-growth inhibitors, secondary recrystallization to a (110)[001] texture can be produced in thin sheets of high-purity $\mathrm{Fe}$ and $\mathrm{Fe}-3 \% \mathrm{Si}$, wherein normal grain growth has been impeded by the sheet thickness. Under these circumstances, the relative energies of the free surfaces 
(i.e., the gas-metal interfaces) of the grains play a determining role in the selection of secondary grains. By proper control of prior mechanical processing, which determines the direction of preferred orientation, and of the furnace atmosphere in the final anneal, which selects the plane of the grains, $\mathrm{Fe}-\mathrm{Si}$ sheets with the (100)[001] cube texture can be produced. It is also possible to produce cube- or Goss-textured $\mathrm{Fe}-\mathrm{Si}$ sheets with a high permeability through the influence of oriented AlN particles during secondary recrystallization.

In hcp metals and alloys, the recrystallization textures of $\mathrm{Zn}$ and $\mathrm{Mg}$ are essentially the same as their rolling textures, according to early studies. Later quantitative texture studies on a dilute $\mathrm{Zn}$ alloy containing $\mathrm{Pb}$ indicated a change of the transverse direction from $[10 \overline{1} 0]$ to $[11 \overline{2} 0]$ upon recrystallization, while the basal pole positions

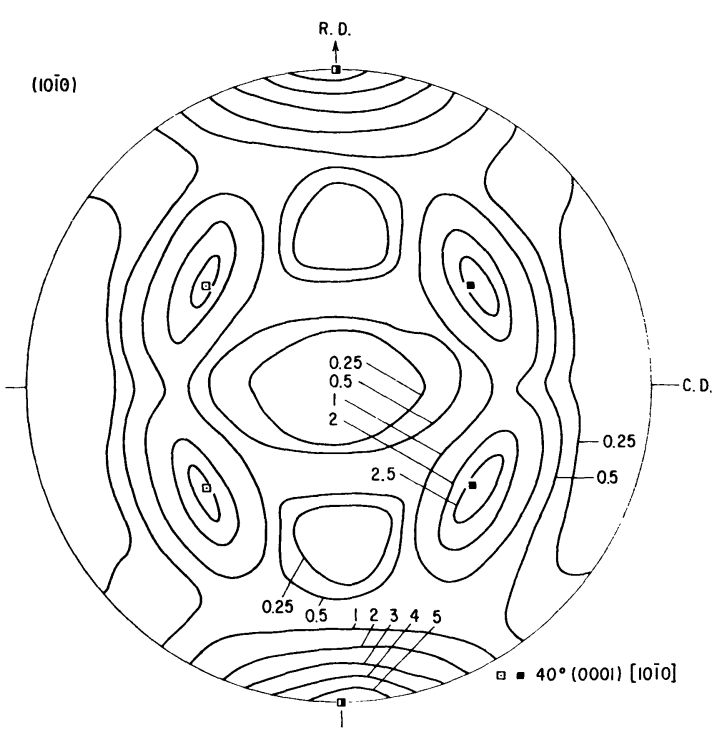

FIGURE 19 Annealing texture of iodide titanium rolled 94 pct at $25^{\circ} \mathrm{C}$, then annealed at $400^{\circ} \mathrm{C}$ for $3125 \mathrm{~min}$. (Hu and Cline, Trans. TMS-AIME, 242, 1013, 1968.)

changed only slightly. This suggests that the reorientation is a [0001] rotation of $30^{\circ}$. Beryllium retains its rolling texture after recrystallization. The annealing behavior of $\mathrm{Ti}$ and $\mathrm{Zr}$ is quite similar. At low temperatures, the nature of the recrystallization texture is apparently the same as that of the rolling texture, although reorientation involving rotations around [0001] is evident. Figure 19 shows the texture of iodide Ti comp'etely recrystallized at $400^{\circ} \mathrm{C}$ (compare with Figure 9). At higher tempera- tures, the annealing textures are distinctly different from the rolling texture. With increasing annealing time or temperature, the texture undergoes continuous changes, which can be described by the simultaneous variation of three angular parameters, $\gamma, \delta$, and $\beta$, as shown in Figures 20 and 21. These textural changes, attributable mainly to normal grain growth, cannot be related to the parent

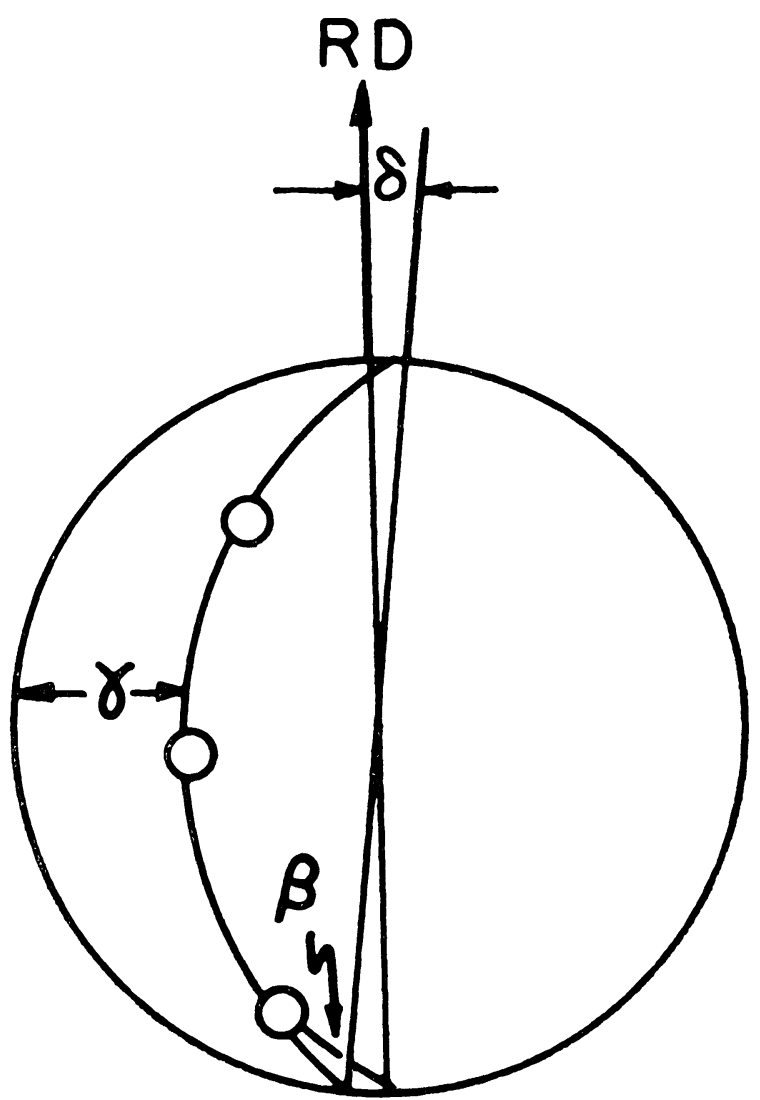

FIGURE 20 Stereographic projection showing the angular parameters on a (1010) pole figure. $\gamma$ is the angle between the rolling plane and $(0001), \delta$ is the angle between the axis of tilt and the rolling direction, and $\beta$ is the angle between the rolling direction and the nearest (1010) pole. (Keeler and Geisler, Trans AIME., 206, 80, 1956.)

texture by simple rotations. Based on the microstructural changes and the mechanical softening observed during the annealing treatment, it has been suggested that the observed textural evolution is probably a result of extensive overlapping of the various stages (recovery, polygonization, recrystallization and grain growth) in the annealing process. It has also been suggested that the recrystallization 


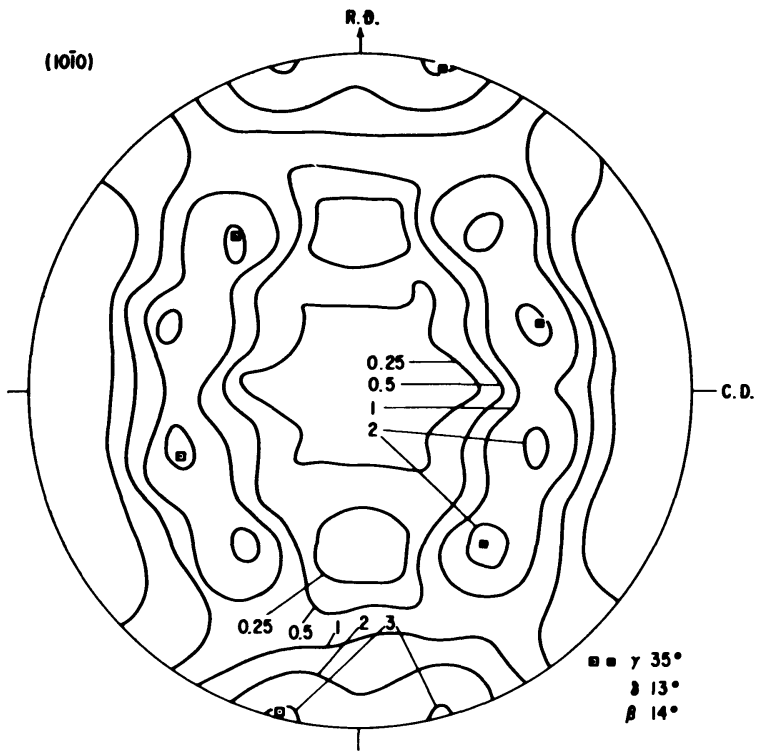

(a)

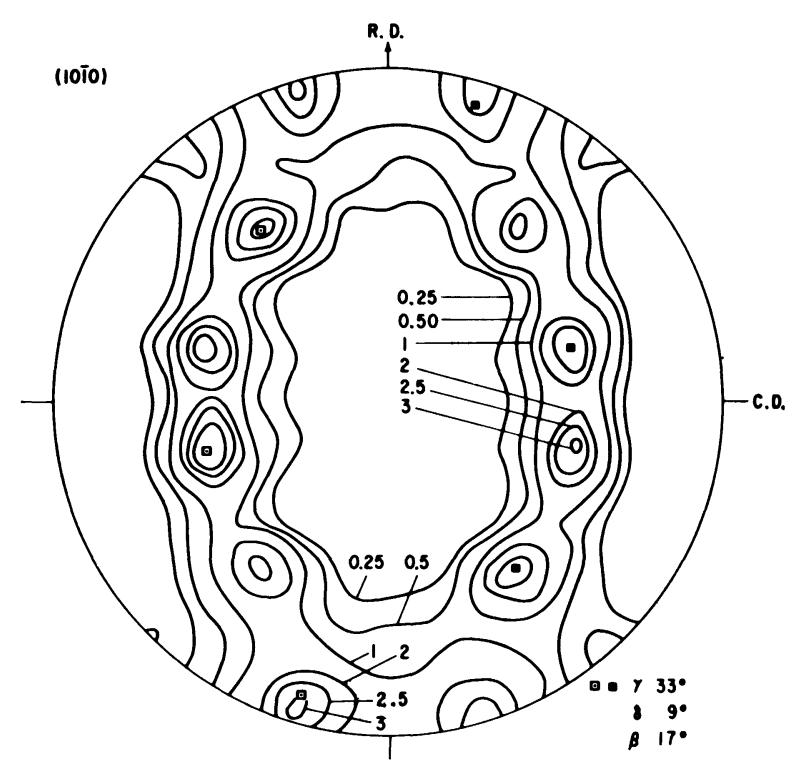

(b)

FIGURE 21 Annealing textures of iodide titanium rolled 94 pct at $25^{\circ} \mathrm{C}$, then annealed at $600^{\circ} \mathrm{C}$ for (a) $1 \mathrm{~min}$, and (b) $25 \mathrm{~min}$. Note changes of the three angular parameters $\gamma, \delta$, and $\beta$ resulting from increased annealing time. (Hu and Cline, Trans. TMS-AIME, 242, 1013, 1968.)

texture of $\mathrm{Ti}$ or $\mathrm{Zr}$ is a result of "compromised growth" between $30^{\circ}$ [0001] and $90^{\circ}$ [1010] rotational relationships, since both of these orientation relationships represent high rates of growth in hcp metals.

The allotropic transformation $\alpha($ hcp $) \rightleftarrows \beta($ bcc) occurs in $\mathrm{Ti}$ and $\mathrm{Zr}$ at approximately $880^{\circ}$ and $860^{\circ} \mathrm{C}$ respectively with a change in orientation according to the Burgers relationships (closestpacked planes and directions of both phases coincide). Annealing at temperatures sufficiently high in the $\beta$-phase region produces a quite different texture, as shown in Figure 22. Based on the Burgers relationships and the same variants for $\alpha \rightarrow \beta \rightarrow \alpha$ transformations, this texture suggests that the $\beta$ phase had a cube texture upon secondary recrystallization.

In orthorhombic $\alpha$-uranium, the recrystallization texture of rolled sheets can be described approximately by four ideal orientations, (113) [1110], (103)[010],(116)[411] , and(100)[010].Among these, (103)[010] is one of the major components of the deformation texture, which is apparently unaltered after recrystallization. The relative prominence of these four orientations appears to depend upon the temperature of prior rolling. For specimens rolled at elevated temperatures, the (113) [1110] orientation dominates the recrystallization texture. Cold-rolled specimens tend to retain their main deformation texture (103)[010] upon recrystallization. Figure 23 shows the texture of a uranium sheet rolled at $300^{\circ} \mathrm{C}$, then recrystallized at $525^{\circ} \mathrm{C}$. The recrystallization texture components may be related to the

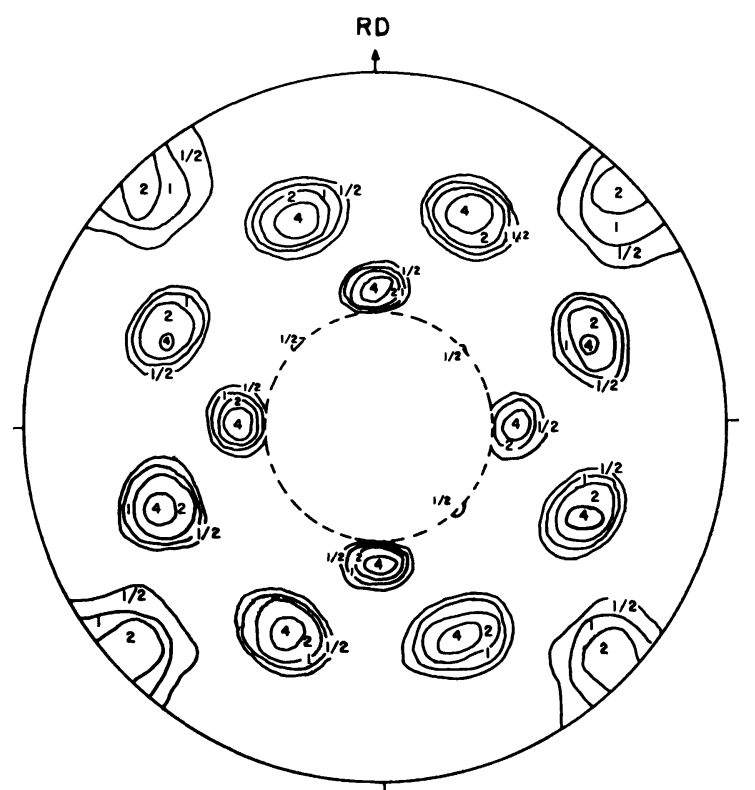

FIGURE 22 (10T̃) pole figure showing texture of titanium cold-rolled $99.7 \mathrm{pct}$, then annealed for $1 \mathrm{hr}$ at $1125^{\circ} \mathrm{C}$ in the $\beta$-phase region. (Keeler and Geisler, Trans. AIME, 206, 80, 1956.) 


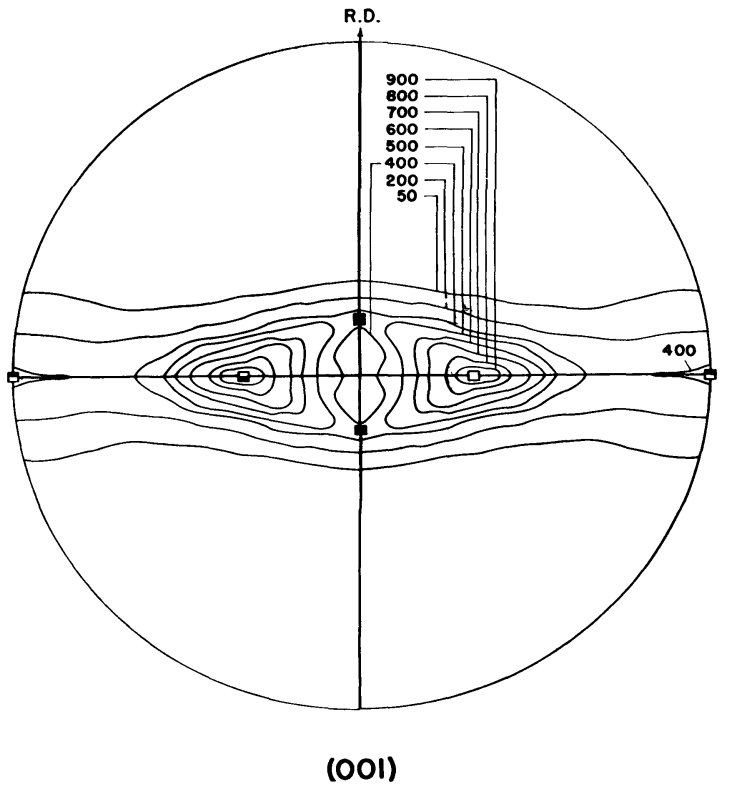

(a)

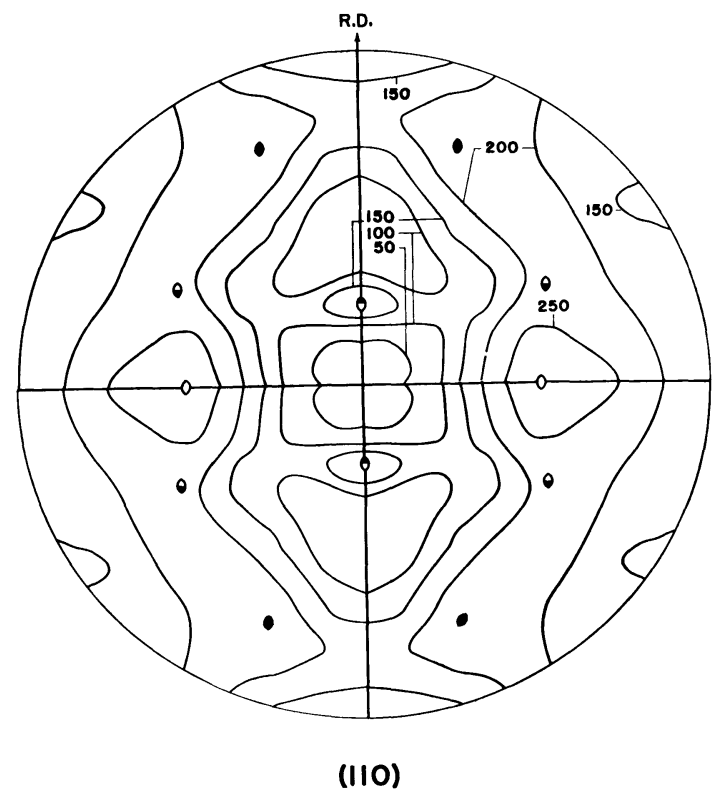

(b)

FIGURE 23 Recrystallization texture of uranium rolled $87 \mathrm{pct}$ at $300^{\circ} \mathrm{C}$, then annealed $1 \mathrm{hr}$ at $525^{\circ} \mathrm{C}$ as shown by (a) (001), and (b) (110) pole figures. Intensity in arbitrary units.

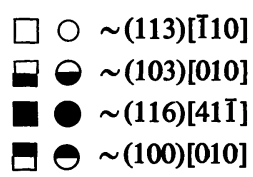

(Mueller, Knott, and Beck, Trans. AIME, 203, 1214, 1955). rolling texture by various rotations around the (001) and $(010)$ poles. As is commonly observed in other metals, grain growth leads to some changes in the annealing texture.

\section{Surface Textures in Recrystallized Sheets}

There have been few studies of the surface recrystallization textures in polycrystalline metals. Based on limited information from single-crystal investigations, surface recrystallization texture depends on the surface deformation texture in much the same manner as does the interior texture. An example indicating such a dependence for surface textures is provided by texture transition in austenitic stainless steels. By rolling a Type 304 stainless steel at $800^{\circ} \mathrm{C}$, a copper-type rolling texture is produced, which recrystallizes into cube texture upon subsequent annealing. However, in the surface layer of the strip the recrystallization texture is not of cube orientation, because the surface rolling texture is not of the copper-type. This is due to the fact that the temperature at the surface during rolling is considerably below $800^{\circ} \mathrm{C}$. When the strip is rolled in a sandwich assembly in which the temperature is more uniform, cube texture is produced through the entire thickness of the strip upon recrystallization.

\section{Recrystallization Textures in Cross-Rolled Sheets}

The reorientations resulting from recrystallization of cross-rolled sheets are generally the same as in straight-rolled or otherwise deformed specimens. The recrystallization texture of cross-rolled $\mathrm{Cu}$ is related to the (110)[22̄3] deformation texture by [111] rotations of $30^{\circ}$. Cross-rolled Mo, being similar to compression-rolled or straight-rolled specimens in annealing behavior, tends to retain its main deformation texture but loses some of the minor components. Recrystallization of crossrolled $\mathrm{Fe}$ occurs first in the minor deformation

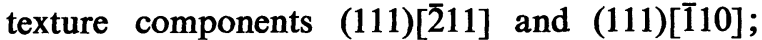
recrystallized grains formed in these minor deformation texture components later grow at the expense of the main deformation texture (100)[011]. Reorientations in connection with these processes can be described as [110] rotation of $25-30^{\circ}$. The recrystallization texture of cross-rolled $\mathrm{Zr}$ is $(0001)[11 \overline{2} 0]$ with reference to the first rolling direction, and (0001)[10 $\overline{1} 0]$ with reference to the second rolling direction. This reorientation is thus a rotation around the hexagonal axis normal to the rolling plane of $30^{\circ}$. 


\section{REFERENCES}

1. F. A. Underwood, Textures in Metal Sheets, MacDonald, London (1961).

2. G. Wassermann and J. Grewen, Texturen Metallischer Werkstoffe, 2. Aufl., Springer-Verlag, Berlin (1962).

3. Recrystallization, Grain Growth and Textures, ASM, Metals Park, Ohio (1965).

4. I. L. Dillamore and W. T. Roberts, Preferred Orientation in Wrought and Annealed Metals, Metallurgical Reviews 10, No. 39 p. 271 (1965).

5. C. S. Barrett and T. B. Massalski, Structure of Metals, 3rd ed., McGraw-Hill, New York, ch. 19-21, (1966).
6. J. Grewen and G. Wassermann eds., Textures in Research and Practice, Springer-Verlag, Berlin (1969).

7. D. J. Blickwede, New Knowledge About Sheet Steel, ASM, Metals Park, Ohio (1970).

8. Ilosciowa Analiza Tekstur, (Proc. International Seminar on Quantitative Analysis of Textures), Cracow, Poland (1971).

9. P. Coulomb, Les Textures dans les Métaux de Réseau Cubique, Dunod, Paris (1972).

10. Metals Handbook, Eighth ed., Vol. 8, ASM, Metals Park, Ohio, p. 229 (1973).

11. Texture, An International Journal, Gordon and Breach, New York, since 1972. 